\title{
Vitamin D in plants: a review of occurrence, analysis, and biosynthesis
}

\author{
Rie B. Jäpelt* and Jette Jakobsen \\ Division of Food Chemistry, National Food Institute, Technical University of Denmark, Søborg, Denmark
}

\section{Edited by:}

Irene Murgia, Università degli Studi di Milano, Italy

Reviewed by:

Gastón F. Stockman, Universidad

Nacional del Sur, Argentina

Lorena Milanesi, Universidad

Nacional del Sur, Argentina

${ }^{*}$ Correspondence:

Rie B. Jäpelt, Division of Food

Chemistry, National Food Institute,

Technical University of Denmark,

Mørkhøj Bygade 19, DK-2860

Søborg, Denmark.

e-mail: riba@food.dtu.dk
The major function of vitamin $D$ in vertebrates is maintenance of calcium homeostasis, but vitamin D insufficiency has also been linked to an increased risk of hypertension, autoimmune diseases, diabetes, and cancer. Therefore, there is a growing awareness about vitamin $D$ as a requirement for optimal health. Vitamin $D_{3}$ is synthesized in the skin by a photochemical conversion of provitamin $D_{3}$, but the necessary rays are only emitted all year round in places that lie below a $35^{\circ}$ latitude. Unfortunately, very few food sources naturally contain vitamin $D$ and the general population as a results fail to meet the requirements. Fish have the highest natural content of vitamin D expected to derive from an accumulation in the food chain originating from microalgae. Microalgae contain both vitamin $D_{3}$ and provitamin $D_{3}$, which suggests that vitamin $D_{3}$ exist in the plant kingdom and vitamin $D_{3}$ has also been identified in several plant species as a surprise to many. The term vitamin $D$ also includes vitamin $D_{2}$ that is produced in fungi and yeasts by UVB-exposure of provitamin $\mathrm{D}_{2}$. Small amounts can be found in plants contaminated with fungi and traditionally only vitamin $\mathrm{D}_{2}$ has been considered present in plants. This review summarizes the current knowledge on sterol biosynthesis leading to provitamin $\mathrm{D}$. It also addresses the occurrence of vitamin $D$ and its hydroxylated metabolites in higher plants and in algae and discusses limitations and advantages of analytical methods used in studies of vitamin D and related compounds including recent advances in analytical technologies. Finally, perspectives for a future production of vitamin D biofortified fruits, vegetables, and fish will be presented.

Keywords: plants, algae, biosynthesis, vitamin D, 25-hydroxy vitamin D, 1,25-dihydroxy vitamin D, sterols, detection

\section{INTRODUCTION}

The main function of vitamin $\mathrm{D}$ is in maintenance and regulation of calcium levels in the body and vitamin D is, therefore, critically important for the development of a healthy skeleton. Thus, vitamin D insufficiency increases the risk of osteoporosis, but has also been linked to an increased risk of hypertension, autoimmune diseases, diabetes, and cancer (Hyppönen et al., 2001; Cantorna and Mahon, 2004; Holick, 2004; Lappe et al., 2007; Pittas et al., 2007; Kendrick et al., 2009). As a result, there is a growing awareness about vitamin $\mathrm{D}$ as a requirement for optimal health. Vitamin $\mathrm{D}_{3}$ is synthesized in the skin by a photochemical conversion of provitamin $\mathrm{D}_{3}$, but the necessary UVB rays ( $290-315 \mathrm{~nm}$ ) are only emitted all year round in places that lie below a $35^{\circ}$ latitude. Thereby, a dietary intake of vitamin D becomes essential, but very few food sources naturally contain vitamin $\mathrm{D}$. The consequence of a low dietary intake and limited vitamin D derived from the sun is that the general populations fail to meet their vitamin D requirements (Brot et al., 2001; Bailey et al., 2010). Fish have the highest natural amount of vitamin $\mathrm{D}_{3}$, which is expected to derive from a high content of vitamin $\mathrm{D}_{3}$ in planktonic microalgae at the base of the food chain (Takeuchi et al., 1991; Sunita Rao and Raghuramulu, 1996a). The occurrence of vitamin $\mathrm{D}_{3}$ in algae suggests that vitamin $\mathrm{D}_{3}$ may exist in the plant kingdom and vitamin $\mathrm{D}_{3}$ has also been identified in several plant species as a surprise to many (Boland et al., 2003). The term vitamin D also includes vitamin $\mathrm{D}_{2}$ that is produced in fungi and yeast by UVBexposure of provitamin $\mathrm{D}_{2}$ and small amounts can be found in plants contaminated with fungi. Traditionally, only vitamin $\mathrm{D}_{2}$ has been considered present in plants.

Two reviews exist on vitamin D compounds in plants (Boland, 1986; Boland et al., 2003). Boland (1986) focused on plant species with vitamin D-like activity, possible functions of vitamin $\mathrm{D}_{3}$ in these plants and metabolism of $1,25(\mathrm{OH})_{2} \mathrm{D}_{3}$ glycosides in animals. Boland et al. (2003) dealt with the detection, presence, and tissue distribution of vitamin $\mathrm{D}_{3}$ compounds in flowering plants, the production of vitamin $\mathrm{D}_{3}$ and derived metabolites in plant cultures, and biological functions of vitamin $\mathrm{D}_{3}$ in flowering plants. However, important questions still remain, especially regarding the biosynthesis of vitamin $\mathrm{D}$ in plants and the present review, therefore, summarizes current knowledge on sterol biosynthesis leading to provitamin D. Before discussing this subject, essential information on vitamin D synthesis, metabolism, biological functions, as well as dietary sources and recommended intake of vitamin $\mathrm{D}$ are described. This review also considers the occurrence of all vitamin $\mathrm{D}$ active compounds existing in plants and algae and discusses the advantages and disadvantages of analytical methods applied for studying vitamin D and related compounds including recent advances 
in analytical technologies. Finally, perspectives for the future production of vitamin D biofortified fruits, vegetables, and fish will be presented.

\section{VITAMIN D}

\section{SYNTHESIS AND ACTIVATION OF VITAMIN D}

Vitamin D is classified into five different classes numbered 2-6. The two main forms of vitamin $\mathrm{D}$ are cholecalciferol (vitamin $\mathrm{D}_{3}$ ) and ergocalciferol (vitamin $\mathrm{D}_{2}$ ), which differ structurally in the side chain, where vitamin $\mathrm{D}_{2}$ has a C22-C23 double bound and an additional methyl group at C24 (Figure 1). The vitamins are secosteroids, i.e., steroids with a broken ring. Vitamin $\mathrm{D}_{2}$ is produced in fungi and yeast by a UVB-exposure of ergosterol (provitamin $\mathrm{D}_{2}$ ), whereas vitamin $\mathrm{D}_{3}$ is produced by UVB-exposure of 7-dehydrocholesterol (provitamin $\mathrm{D}_{3}$ ) in the skin (Figure 1). The conversion to the previtamin $\mathrm{D}$ happens by an exposure to sunlight at 290-315 nm (UVB) (Figure 1). Conversion also happens at lower wavelengths, but solar radiation below $290 \mathrm{~nm}$ is prevented from reaching the earth's surface by the ozone layer in the stratosphere (MacLaughlin et al., 1982). High-energy photons are absorbed in the conjugated 6,7-diene in the B-ring of ergosterol and 7-dehydrocholesterol, which results in a ring opening at C9 and C10 to form previtamin D (Havinga, 1973). Previtamin D is biologically inactive and thermodynamically unstable and undergoes a transformation to vitamin $\mathrm{D}$ in a temperature-dependent manner (Havinga, 1973). Previtamin $\mathrm{D}_{3}$ will by prolonged UVB-exposure be converted to the inactive forms lumisterol and tachysterol to protect the organism from vitamin D toxicity (Holick et al., 1981). Synthesis of vitamin D in the skin depends on, e.g., season and latitude. The solar zenith angle increases during the winter months and with latitude. When the solar zenith angle is large, filtration of sunlight through the ozone layer takes place through an increased path length, decreasing the UVB photons that penetrate into the earth's surface. As a result, the rays necessary for the vitamin $\mathrm{D}$ production are only emitted all year round in places that lie below $35^{\circ}$ latitude (Holick, 2003). In the northern hemisphere this is, e.g., Northern Africa and Los Angeles.

Vitamin D from the skin diffuses into the blood, where it is transported by vitamin D binding protein (DPB) to the liver, whereas vitamin $\mathrm{D}$ from the diet is absorbed in the small intestine and transported to the liver via chylomicrons and DBP. Vitamin D is biologically inactive and the activation involves two hydroxylations (Figure 1). First, vitamin D is hydroxylated in the liver at C-25 by a 25-hydroxylase to yield 25-hydroxyvitamin D (25OHD) (Jones et al., 1998; Prosser and Jones, 2004). The activity of 25 -hydroxylase is poorly regulated and dependent primarily on the concentration of vitamin

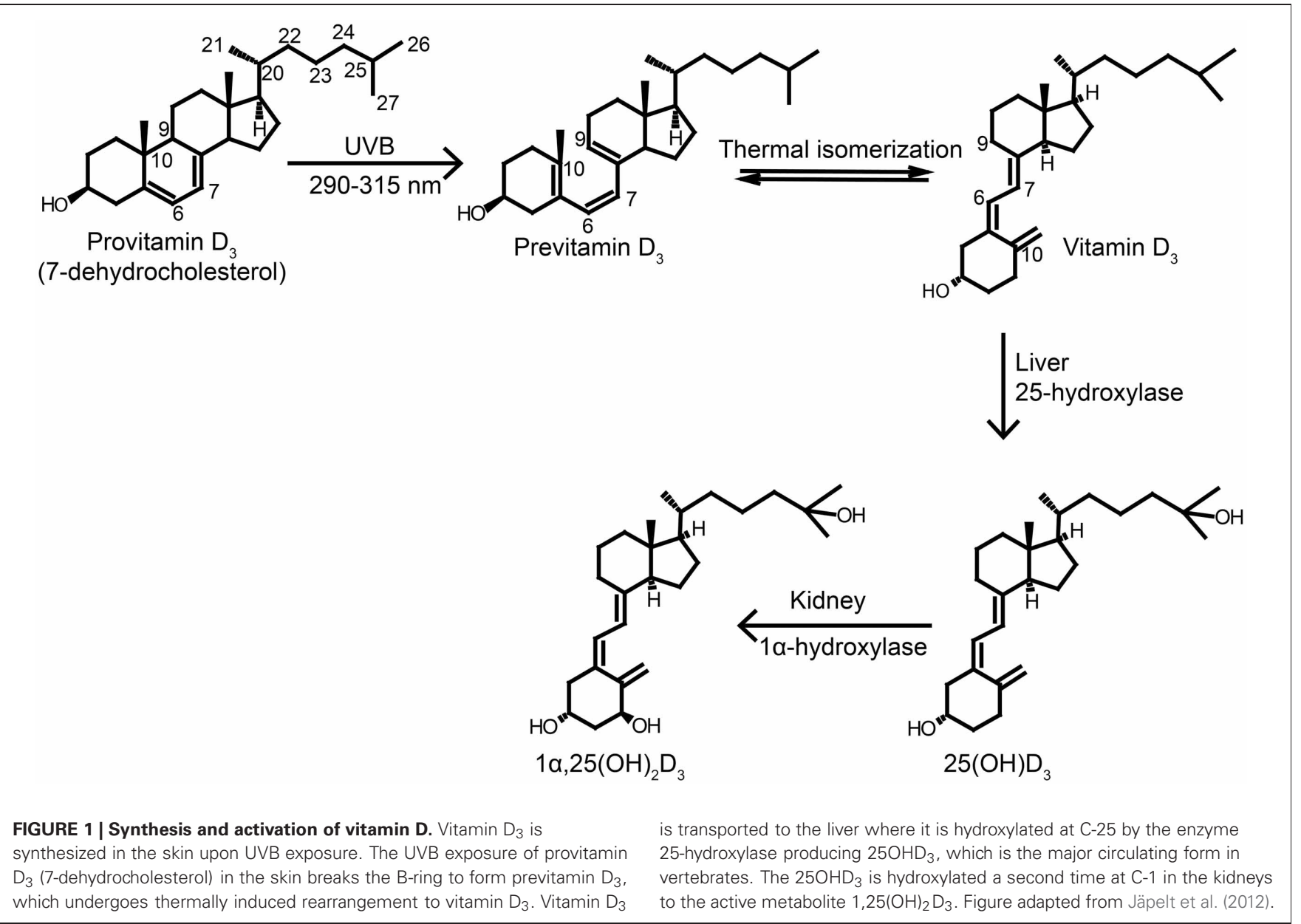


D (Bhattacharyya and DeLuca, 1973). The circulating concentration of $25 \mathrm{OHD}$ is the accepted biomarker for vitamin $\mathrm{D}$ status, as this reflects both dietary intake and skin production. The optimal vitamin D status has been a subject of debate and there is no general standard (Dawson-Hughes et al., 2005). Some studies indicate that vitamin $D_{2}$ and vitamin $D_{3}$ acts equally in maintaining vitamin D status (Rapuri et al., 2004; Holick et al., 2008), while others indicate that vita$\min \mathrm{D}_{2}$ is less effective than vitamin $\mathrm{D}_{3}$ (Trang et al., 1998; Armas et al., 2004). After production of 25OHD in the liver, it is transported, to the kidneys bound to DPB. In passing through the kidneys, 25OHD is hydroxylated at the $\alpha$-position of C- 1 by $1 \alpha$-hydroxylase to generate $1 \alpha, 25$-dihydroxyvitamin $\mathrm{D}\left[1,25(\mathrm{OH})_{2} \mathrm{D}\right]$ (Jones et al., 1998; Prosser and Jones, 2004). The bioconversion of $25 \mathrm{OHD}$ to $1,25(\mathrm{OH})_{2} \mathrm{D}$ is strictly regulated by serum calcium and serum phosphorus levels, $1,25(\mathrm{OH})_{2} \mathrm{D}$ blood levels and parathyroid hormone (PTH) (Prosser and Jones, 2004).

\section{BIOLOGICAL EFFECT OF VITAMIN D}

The main function of vitamin $\mathrm{D}$ is in maintenance and regulation of calcium and phosphorus levels in the body (DeLuca, 2004). Low blood calcium stimulates release of PTH from the parathyroid gland. In turn, PTH stimulates $1 \alpha$-hydroxylase in the kidneys to produce $1,25(\mathrm{OH})_{2} \mathrm{D}$, which then increases serum calcium and phosphorus concentrations by acting on three targets: increased absorption from the intestine, reabsorption in the kidneys and mobilization from bones (DeLuca, 2004). The active metabolite, $1,25(\mathrm{OH})_{2} \mathrm{D}$, mediates its biological effect by binding to the vitamin $\mathrm{D}$ receptor (VDR). The mechanisms by which $1,25(\mathrm{OH})_{2} \mathrm{D}$ performs its biological effect can be divided into two: a genomic and a non-genomic (Norman et al., 1992). The genomic mechanism is mediated by nuclear VDRs that on binding to $1,25(\mathrm{OH})_{2} \mathrm{D}$ interacts with DNA to modulate gene expression, while the non-genomic pathway includes interactions with VDRs in the cell membrane (Norman et al., 1992). The non-genomic pathway is usually working very fast, i.e., within seconds and minutes, whereas genomic responses typically take a few hours to days (Norman, 2006).

\section{DIETARY INTAKE AND RECOMMENDED DAILY INTAKE OF VITAMIN D}

Because the body produces vitamin $\mathrm{D}_{3}$, vitamin $\mathrm{D}$ does not meet the classical definition of a vitamin. Generally, fish have the highest natural amount of vitamin $\mathrm{D}_{3}$, e.g., salmon contains $30 \mu \mathrm{g} / 100 \mathrm{~g}$ and tuna $2.9 \mu \mathrm{g} / 100 \mathrm{~g}$ (Danish Food Composition Databank, revision. 7,2008$)$. Other sources of vitamin $\mathrm{D}_{3}$ are meat $(\sim 0.6 \mu \mathrm{g} / 100)$, egg $(\sim 1.75 \mu \mathrm{g} / 100)$ and milk products $(\sim 0.1 \mu \mathrm{g} / 100)$ (Danish Food Composition Databank, revision. $7,2008)$. The content of vitamin $\mathrm{D}$ in food of animal origin depends on what the animal has been fed (Mattila et al., 1999; Graff et al., 2002; Jakobsen et al., 2007). The main compound in food is vitamin $\mathrm{D}_{3}$, but the metabolites, which are part of the metabolic pathway in vertebrates also exist (Mattila et al., 1995a,b; Clausen et al., 2003; Jakobsen and Saxholt, 2009). The potency of 25OHD has often been attributed to possess five times the potency of vitamin D (Reeve et al., 1982; Cashman et al.,
2012). This value is implemented in food composition databases. However, there is no consensus on the conversion factor that should be used for $25 \mathrm{OHD}$ to calculate the vitamin D activity mainly because of very limited human data (Jakobsen, 2007; Cashman et al., 2012). The potency of $1,25(\mathrm{OH})_{2} \mathrm{D}$ has been attributed to ten relative to vitamin D (Tanaka et al., 1973), but this value is not implemented in food composition tables, as there is no specific composition data available for $1,25(\mathrm{OH})_{2} \mathrm{D}$. Food sources of vitamin $\mathrm{D}_{2}$ are very limited and wild mushrooms are one of the only significant sources of vitamin $\mathrm{D}_{2}$ (Mattila et al., 1994, 2002; Teichmann et al., 2007). However, milk from dairy cows contains a significant although low amount of vitamin $\mathrm{D}_{2}$, which is expected to derive from grass and hay (Jakobsen and Saxholt, 2009). Vitamin D fortification of selected foods has been accepted as a strategy to improve the vitamin D status of the general population both in the United States and in many European countries. Milk and margarine are the primary products that are enriched with vitamin D (Natri et al., 2006), but also orange juice (Calvo et al., 2004), bread (Natri et al., 2006; Hohman et al., 2011), cheese and yoghurt may be enriched (Holick, 2011). This area is regulated differently in each country. Fortification may either be voluntary or mandatory and the levels added vary accordingly.

The American dietary vitamin D recommendations are $15 \mu \mathrm{g} /$ day for the age group 1-70 years including women who are pregnant or lactating and increases to $20 \mu \mathrm{g} /$ day for adults older than 70 years (Institute of Medicine, 2011). An adequate intake is estimated to $10 \mu \mathrm{g} /$ day for infants (Institute of Medicine, 2011). Without sufficient vitamin D humans will develop a deficiency disease. Growing children develop rickets because of failure in calcification of cartilaginous growth plates. Osteomalacia develops in adults during prolonged vitamin $\mathrm{D}$ deficiency, where the newly formed uncalcified bone tissue gradually replaces the old bone tissue with weakened and soft bones as a consequence. Excessive vitamin D consumption can result in toxicity. Toxic levels are not obtained by a usual diet, but by excessive consumption of vitamin D supplements or over-fortification of food. Vitamin D intoxication is primarily due to hypercalcemia caused by increased intestinal absorption of calcium, together with increased resorption of bones. If the vitamin D exposure is prolonged, deposition of calcium in soft tissues particularly in arterial walls and in the kidney occurs. An upper intake level for vitamin $\mathrm{D}$ has been set to $100 \mu \mathrm{g}$ for adults and children aged 9 years and older (Institute of Medicine, 2011).

\section{THE DISCOVERY OF VITAMIN D IN PLANTS}

In 1924 two groups independently discovered that light exposure of inert food could result in antirachitic activity (could cure rickets) (Hess and Weinstock, 1924; Steenbock and Black, 1924). Otherwise, inert foods such as linseed oil, cottonseed oil, wheat and lettuce were made antirachitic when exposed to light from a mercury lamp (Hess and Weinstock, 1924, 1925). The question at that time was: "What was the substance in vegetables and crops that could be activated by light exposure?" Later, vitamin $\mathrm{D}_{2}$ was identified from solutions of irradiated ergosterol (Askew et al., 1930; Windaus, 1931). The high concentrations of ergosterol in fungi and as a result in plants contaminated with fungi 
led to a general perception of vitamin $\mathrm{D}_{2}$ as a plant form of vitamin $\mathrm{D}$. Vitamin $\mathrm{D}_{3}$ has on the other hand been considered absent from plants. However, grazing animals in several parts of the world develop calcium intoxication, similar to that caused by vitamin $\mathrm{D}$ toxicity, from consuming particular plants (Mello, 2003). This is believed to be due to vitamin $D_{3}$ or a metabolite of vitamin $D_{3}$ present in the plants that stimulate calcium absorption producing hypercalcemia and deposition of calcium in soft tissue including aorta, heart, kidneys, intestines, and uterus (Mello, 2003). Most work has been made on the plant Solanum glaucophyllum Desf. (S. glaucophyllum) that causes calcium intoxication of livestock in South America (Mello, 2003). Controlled studies with various animals including rabbits (Mautalen, 1972; Humphreys, 1973; Dallorso et al., 2008), chickens (Wasserman et al., 1976a; Weissenberg et al., 1989) and rats (Uribe et al., 1974; Basudde and Humphreys, 1976) demonstrated that S. glaucophyllum leaves or extracts caused increased absorption of calcium and phosphorus similar to vitamin D. Cestrum diurnum L. (C. diurnum) and Trisetum flavescens Beauv. (T. flavescens) are also known to cause calcium intoxication very similar to S. glaucophyllum (Wasserman et al., 1975; Peterlik et al., 1977; Rambeck et al., 1979). Studies with these plants later led to the identification of vitamin $\mathrm{D}_{3}$ and related compounds in plant tissue.

\section{STEROLS-PRECURSORS OF VITAMIN D}

Sterols are essential for all eukaryotes. They are components of membranes and have a function in regulation of membrane fluidity and permeability (Piironen et al., 2000). Sterols also play an important role as precursors of many steroid hormones including vitamin $\mathrm{D}$ and brassinosteroids as well as for a wide range of secondary metabolites such as saponins and glycoalkaloids. Sterols are made up of four rings designated A, B, C, and D with one or more double bonds, a long flexible side chain at C17, a hydroxyl group attached to $\mathrm{C} 3$ and a variety of substituents (Figure 2). The hydroxy group at C3 can be esterified with either a longchain fatty acid or a phenolic acid to give a steryl ester (Figure 3). Steryl esters are present in all plants, most often localized in the cytoplasm of plant cells (Benveniste, 2002), and represent a storage form of sterols (Piironen et al., 2000). The 3-hydroxy group

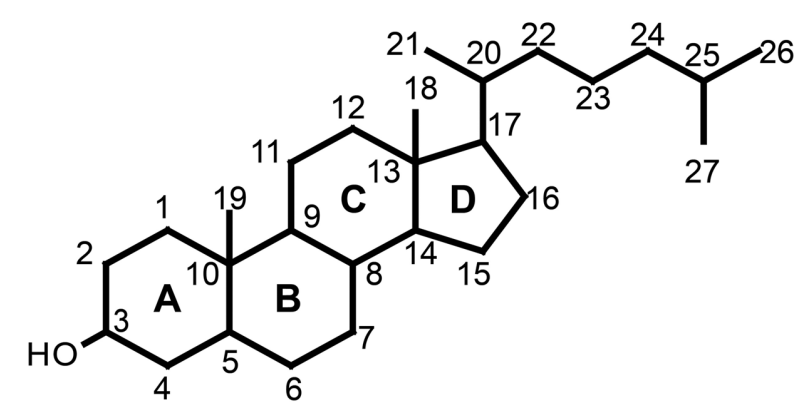

FIGURE 2 | The core structure of sterols is a fused four ring (A,B,C, and D ring). Various groups are added to the core structure to generate a variety of sterols. Numbering of the carbon atoms is according to the 1989 IUPAC-IUB recommendations. can also be linked to a carbohydrate forming a steryl glycoside (Figure 3). Steryl glycosides usually consist of a mixture differing in carbohydrate moiety and esterification of the sugar by a fatty acid can give rise to an acetylated steryl glycoside (Figure 3). Especially, plants from the Solanaceae family show a unique abundance of glycosides (Moreau et al., 2002; Potocka and Zimowski, 2008).

Generally, sterols can be divided into three groups according to the alkylations at the $\mathrm{C} 24$ position in the side chain: 24-desmethylsterols (without an alkyl group), 24-demethylsterols (with one methyl group) and 24-ethylsterols (with one ethyl group). 24-desmethylsterols are typical for animals, whereas the 24-demethylsterols and 24-ethylsterols are typical for plants and fungi. Animals and fungi accumulate the major end product sterols, cholesterol (24-desmethylsterol) and ergosterol (24-demethylsterol), whereas the plant kingdom in comparison produces a wide range of sterols. More than 250 sterols have been found in plants (Hartmann, 2004), but sitosterol, campesterol, and stigmasterol normally predominates (Lagarda et al., 2006). Plant sterols typically have a double bond between C5 and $\mathrm{C} 6$ in the $\mathrm{B}$ ring and are called $\Delta 5$-sterols. Sterols with a $\Delta 5$ nucleus are the most common, but $\Delta 7$-sterols, $\Delta 5,7$-sterols, and $\Delta 22$-sterols also occur (Piironen et al., 2000). Plant tissues contain an average quantity of $1-3 \mathrm{mg}$ sterols per gram dry weight (Schaller, 2004). The sterol composition of plant species is genetically determined and varies considerably (Schaller, 2003). The model plant, Arabidopsis thaliana, e.g., has a sterol composition of $64 \%$ sitosterol, 11\% campesterol, 6\% stigmasterol, 3\% isofucosterol, $2 \%$ brassicasterol and $14 \%$ of other minor sterols (Schaeffer et al., 2001). Cholesterol is the major sterol in animals, but is also present in plants. Usually, cholesterol accounts for $1-2 \%$ of total plant sterols, but higher levels are present in especially Solanaceae (Whitaker, 1988, 1991; Zygadlo, 1993; Moreau et al., 2002; Jäpelt et al., 2011b). It has been suggested that cholesterol serves as a precursor of glycoalkaloids (Bergenstråhle et al., 1996) and ecdysteroids (Dinan, 2001) in these plants.

\section{VITAMIN D BIOSYNTHESIS}

Vitamin $\mathrm{D}$ biosynthesis is taking place along the normal sterol pathway, i.e., vitamin $\mathrm{D}_{2}$ is formed by UVB exposure of ergosterol and vitamin $\mathrm{D}_{3}$ by UVB exposure of 7-dehydrocholesterol. Therefore, we need to understand how its sterol precursors are formed in order to understand how vitamin D synthesis takes place in plants. Sterol biosynthesis can be divided into two parts. The first part is the mevalonic acid pathway. All isoprenoid compounds, including sterols, are formed via the mevalonic acid pathway from the common C5 isoprene building blocks isopentyl diphosphate (IPP) and its isomer dimethylallyl diphosphate (DMAPP) (Figure 4). One molecule DMAPP and two molecules IPP is assembled to farnesyl pyrophosphate (FPP) (Figure 4). Finally, two molecules FPP are combined to make squalene (Hartmann, 2004). Cyclization of squalene is via the intermediate 2,3-oxidosqualene, that forms either lanosterol or cycloartenol via a series of enzymatic cyclizations (Figures 4, 5). Animals and fungi forms lanosterol catalyzed by lanosterol synthase (LAS) and plants form cycloartenol catalyzed by cycloartenol synthase (CAS) (Figure 5). Several reviews have covered the enzymes and 


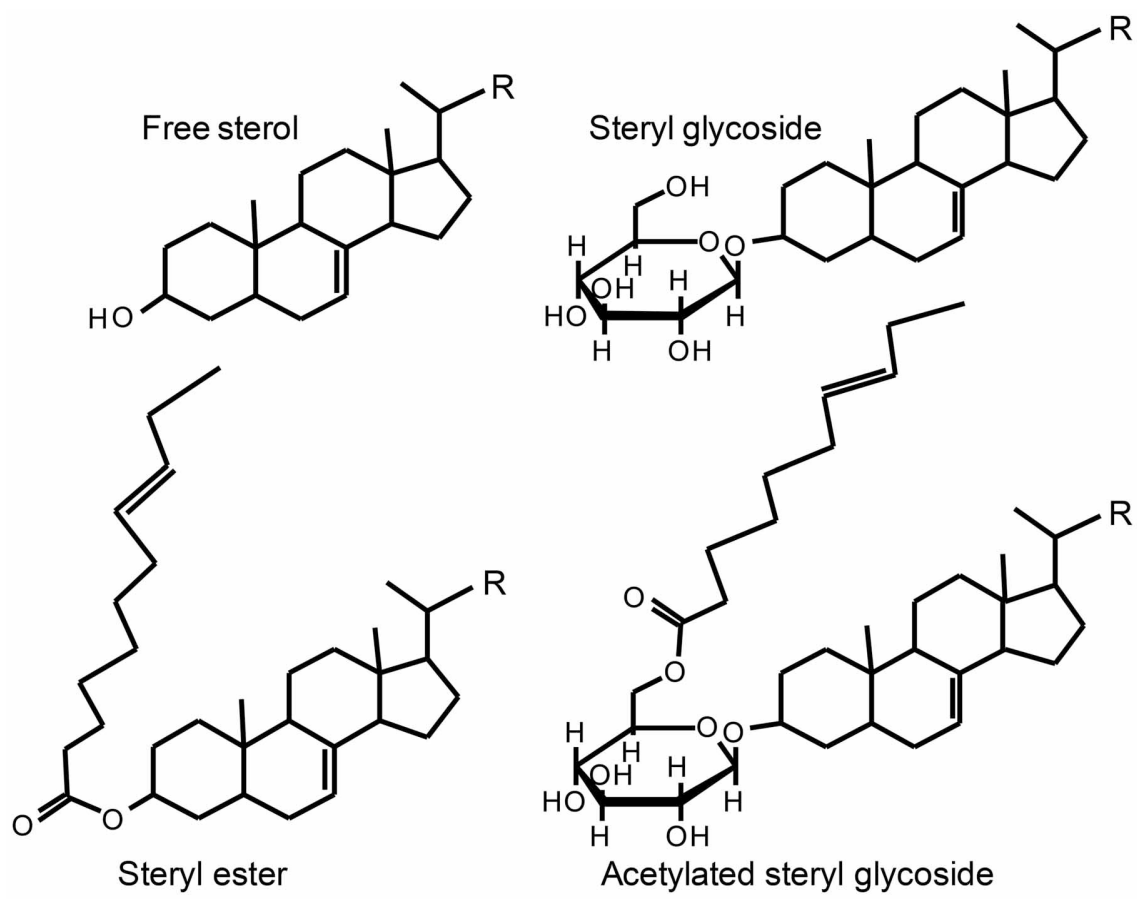

FIGURE 3 | Basic structures of free sterol and its conjugates. The side chain R varies between various sterols. Figure Adapted from Toivo et al. (2001).

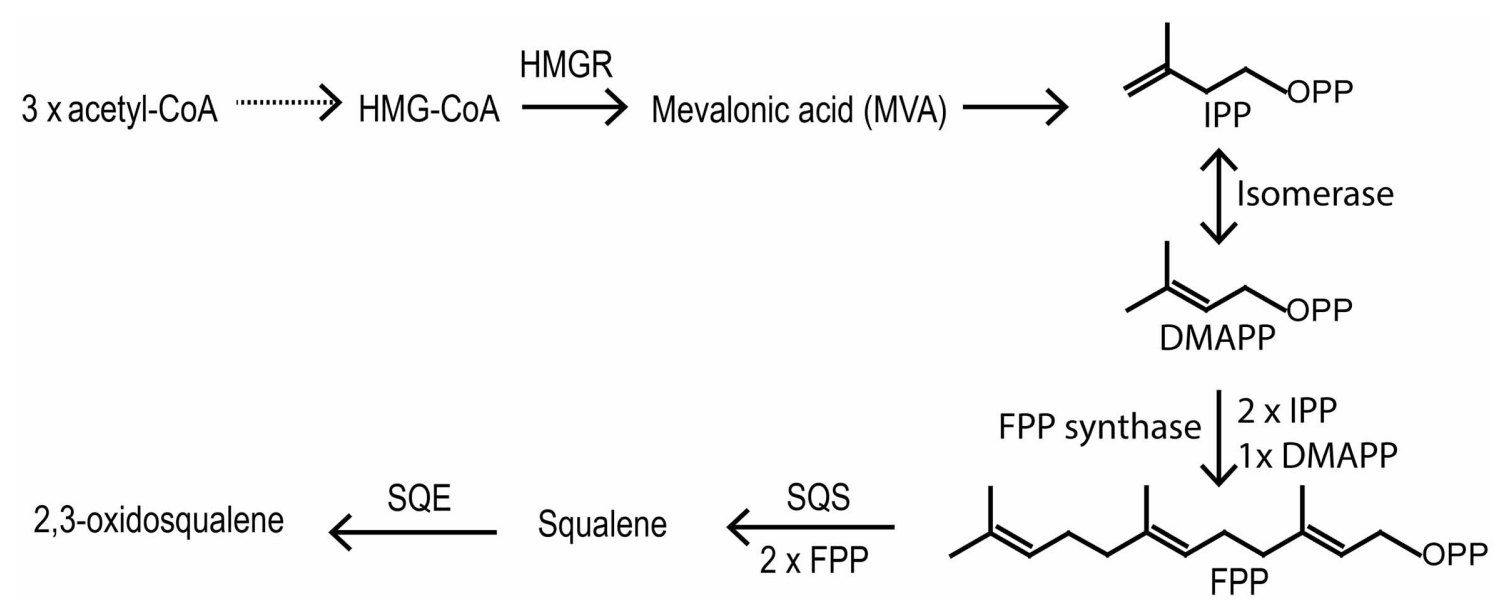

FIGURE 4 | First part of the biosynthetic pathway of sterols. Solid arrows mean one reaction and doted arrow multiple steps. HMG-CoA, 3-hydroxymethyl-3-glutaryl coenzyme A; HMGR, HMG-CoA reductase; IPP,
Isopentyl pyrophosphate; DMAPP, Dimethylalkyl pyrophosphate; FPP, Farnesyl pyrophosphate; SQS, squalene synthase; SQE, squalene epoxidase. genes involved in the sterol pathway (Benveniste, 1986, 2002, 2004; Bach and Benveniste, 1997; Schaller, 2003, 2004; Hartmann, 2004; Nes, 2011). Therefore, only the steps downstream from 2,3-oxidosqualene relevant for the biosynthesis of vitamin $\mathrm{D}_{2}$ and vitamin $\mathrm{D}_{3}$ will be included in the present review.

\section{STEROL BIOSYNTHESIS LEADING TO VITAMIN D 3 -ANIMALS}

The major end product of the animal sterol pathway is cholesterol synthesized via lanosterol (Figure 5). The conversion of lanosterol to cholesterol requires nine different enzymes (Risley, 2002; Nes, 2011) and involves removal of three methyl groups, reduction of double bonds and migration of a double bond in lanosterol to a new position in cholesterol (Waterham et al., 2001). Two intersecting routes to cholesterol have been postulated (Nes, 2011). The direction of the pathway is determined by the stage at which the double bond at C24 in the sterol side chain is reduced (Nes, 2011). In the Kandutsch-Russell pathway, the reduction of the $\mathrm{C} 24$ double bond happens as the first step 


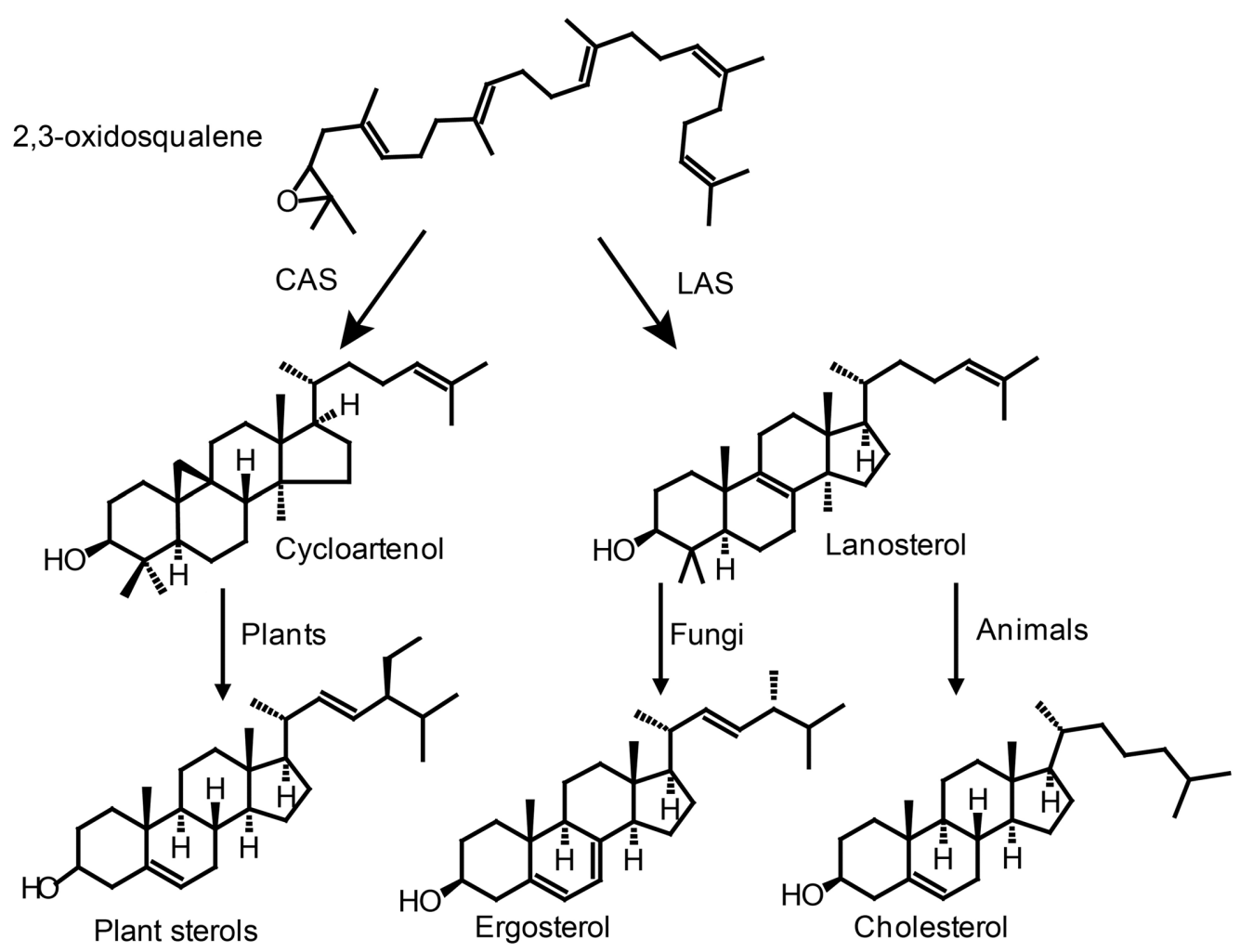

FIGURE 5 | Cyclization of 2,3-oxidosqualene forms either lanosterol or cycloartenol via a series of enzymatic cyclizations leading to sterols in plants, fungi and animals. CAS, cycloartenol synthase; LAS, lanosterol synthase.

(Kandutsch and Russell, 1960). The final precursor for cholesterol in the Kandutsch-Russell pathway is 7-dehydrocholesterol and the last step a reduction of the $\Delta 7$ double bond by a $\Delta^{5,7}$-sterol$\Delta^{7}$-reductase (7-dehydrocholesterol reductase) to give cholesterol (Figure 6). Desmosterol is the ultimate precursor of cholesterol in the Bloch pathway (Bloch, 1983) (Figure 6). Desmosterol is converted to cholesterol in the final step of the pathway by a sterol- $\Delta^{24}$-reductase. However, the sequence of reactions in the cholesterol biosynthetic pathway may vary (Waterham et al., 2001). Alternate routes exist because reduction of the C24-C25 double bond in the side chain by sterol $\Delta^{24}$-reductase can occur on all intermediates between lanosterol and desmosterol in the Bloch Pathway, giving rise to various intermediates (Bae and Paik, 1997). These intermediates can serve as substrates in the Kandutsch-Russell pathway as shown for 7-dehydrodesmosterol in Figure 6.

\section{STEROL BIOSYNTHESIS LEADING TO VITAMIN $D_{2}$-FUNGI}

The major sterol end product in fungi is ergosterol synthesized via lanosterol (Figure 5). The yeast Saccharomyces cerevisiae has been used as a model system for the elucidation of the ergosterol pathway and all enzymes involved have been identified (Lees et al., 1995). Cholesterol and ergosterol share the pathway until zymosterol (Figure 6) (Lees et al., 1995). However, sterols from fungi differ from animal sterols by the presence of a methyl group at C24. The alkylation of the side chain is catalyzed by $S$-adenosylmethionine sterol methyltransferase (ERG6) that in S. cerevisiae converts zymosterol into fecosterol (Figure 7) (Bach and Benveniste, 1997). Plants are not known to produce ergosterol, and any vitamin $\mathrm{D}_{2}$ present is probably derived from endophytic fungi or a fungal infection.

\section{STEROL BIOSYNTHESIS LEADING TO VITAMIN D D $_{3}$ PLANTS}

The enzymes involved in 24-demethylsterol and 24ethylsterol synthesis have been identified in the model plant Arabidopsis thaliana. However, the biosynthetic pathway for 24desmethylsterols, such as cholesterol and 7-dehydrocholesterol, remains unknown. This is probably due to the fact that these are minor sterols in Arabidopsis as well as in most other plants. Experiments with biosynthetic mutants and transgenic plants indicate that the enzymes regulating 24-demethylsterols and 24-ethylsterols also are involved in the regulation of 24-desmethylsterols. Within this chapter a hypothetical biosynthetic route to 24-desmethylsterols with cholesterol as end product will be presented (Figure 8).

\section{Lanosterol as an alternative precursor for sterols}

Plant sterols are synthesized via cycloartenol catalyzed by CAS (Figure 5). However, evidence exists of the presence of putative LAS genes in Arabidopsis thaliana (Kolesnikova et al., 2006; Suzuki et al., 2006; Ohyama et al., 2009), Panax Ginseng (Suzuki 


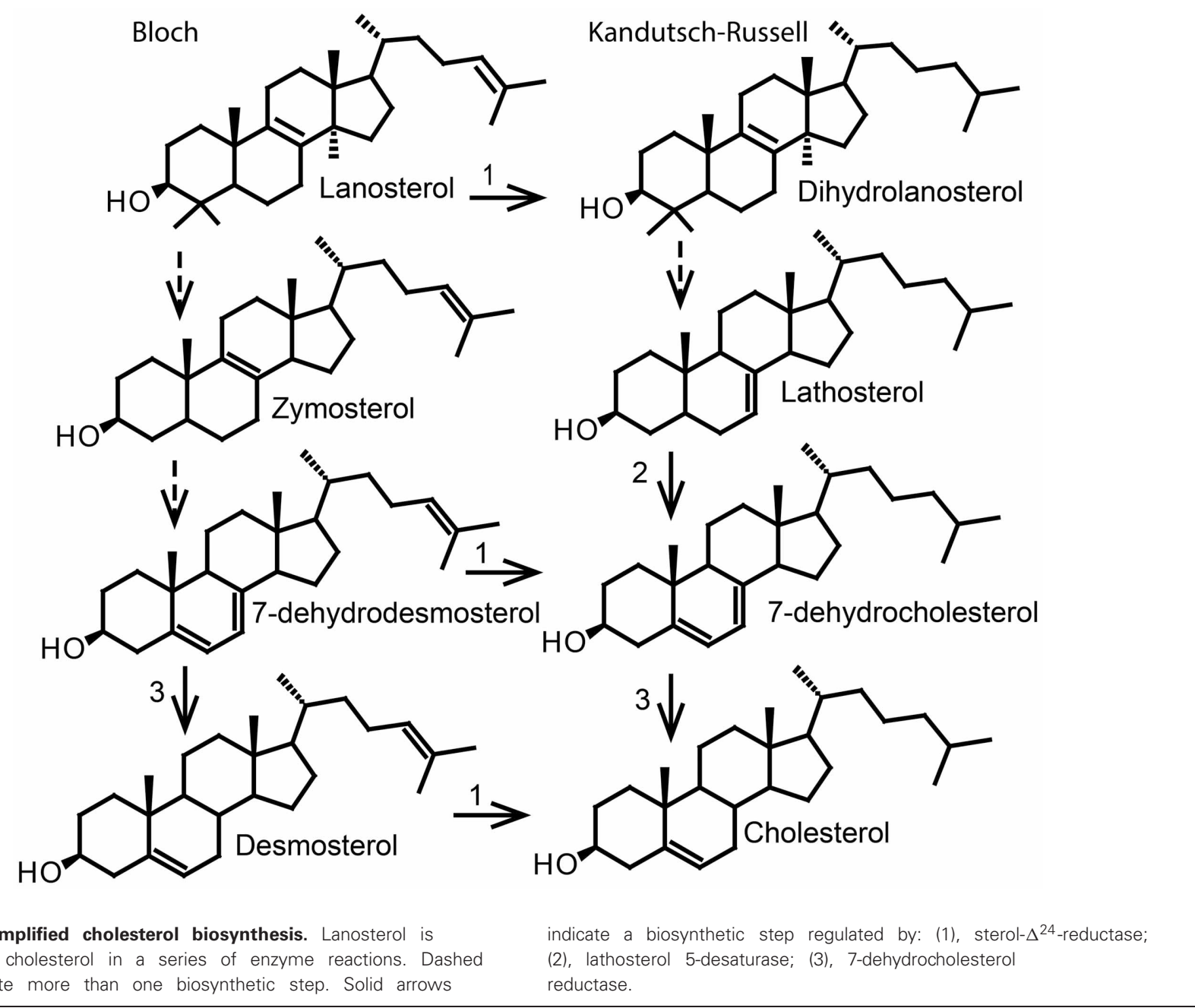

FIGURE 6 | Simplified cholesterol biosynthesis. Lanosterol is
converted to cholesterol in a series of enzyme reactions. Dashed arrows indicate more than one biosynthetic step. Solid arrows reductase.

et al., 2006) and Lotus japonica (Kolesnikova et al., 2006; Sawai et al., 2006). Consequently, lanosterol synthesized by LAS in plants may act as an alternative intermediate for sterol synthesis. A lanosterol pathway to plant sterols has been demonstrated in Arabidopsis (Ohyama et al., 2009). The lanosterol pathway only contributed to $1.5 \%$ of the sitosterol biosynthesis, but this was increased to $4.5 \%$ by LAS overexpression (Ohyama et al., 2009). Thus, sterols in plants may be synthesized by two biosynthetic routes, via cycloartenol and/or via lanosterol. As a result cholesterol and 7-dehydrocholesterol may be formed in plants through lanosterol as is known from animals (Figure 6). In future experiments, it has to be confirmed if plants producing high amounts of these sterols such as Solanaceae, have a more efficient LAS enzyme.

\section{S-adenosylmethionine sterol methyltransferases (SMTs)}

Sterols from plants differ from animal sterols by the presence of a methyl or an ethyl group at C24. S-adenosylmethionine sterol methyltransferases (SMTs) catalyze the transfer of two carbon atoms from $S$-adenosyl methionine to make the 24-alkylations and are considered important regulatory steps in the biosynthesis of sterols in plants (Schaller, 2003). The alkyl substituent at C24 is the product of either one single carbon addition or two single carbon additions. The two methyl additions are performed as distinct steps in the pathway and two classes of SMTs exist: SMT1 and SMT2 (Figure 8). SMT1 preferably catalyze the first methylation of cycloartenol to give 24-methylenecycloartenol (Hartmann, 2004) (Figure 8). The ratio of cholesterol and the major plant sterols sitosterol, stigmasterol and campesterol has been shown to be controlled by the activity of SMT1 (Hartmann, 2004). In Arabidopsis thaliana plants, bearing a SMT1 knockout, cholesterol was the major sterol, composing $26 \%$ of total sterols, compared with $6 \%$ in wild-type plants (Diener et al., 2000 ). The $s m t 1$ mutant displayed poor growth and fertility, root sensitivity to $\mathrm{Ca}^{2+}$ and loss of proper embryo morphogenesis (Diener et al., 2000). SMT1 overexpressing tobacco plants do in contrast have a reduced content of cholesterol and no visual phenotype (Schaeffer et al., 2000; Sitbon and Jonsson, 2001; Holmberg et al., 2002). Similar results have been observed in transgenic potato (Solanum tuberosum cv Désirée) overexpressing SMT1 (Arnqvist et al., 2003). These results indicate that the production of high amounts of cholesterol in plants results from 


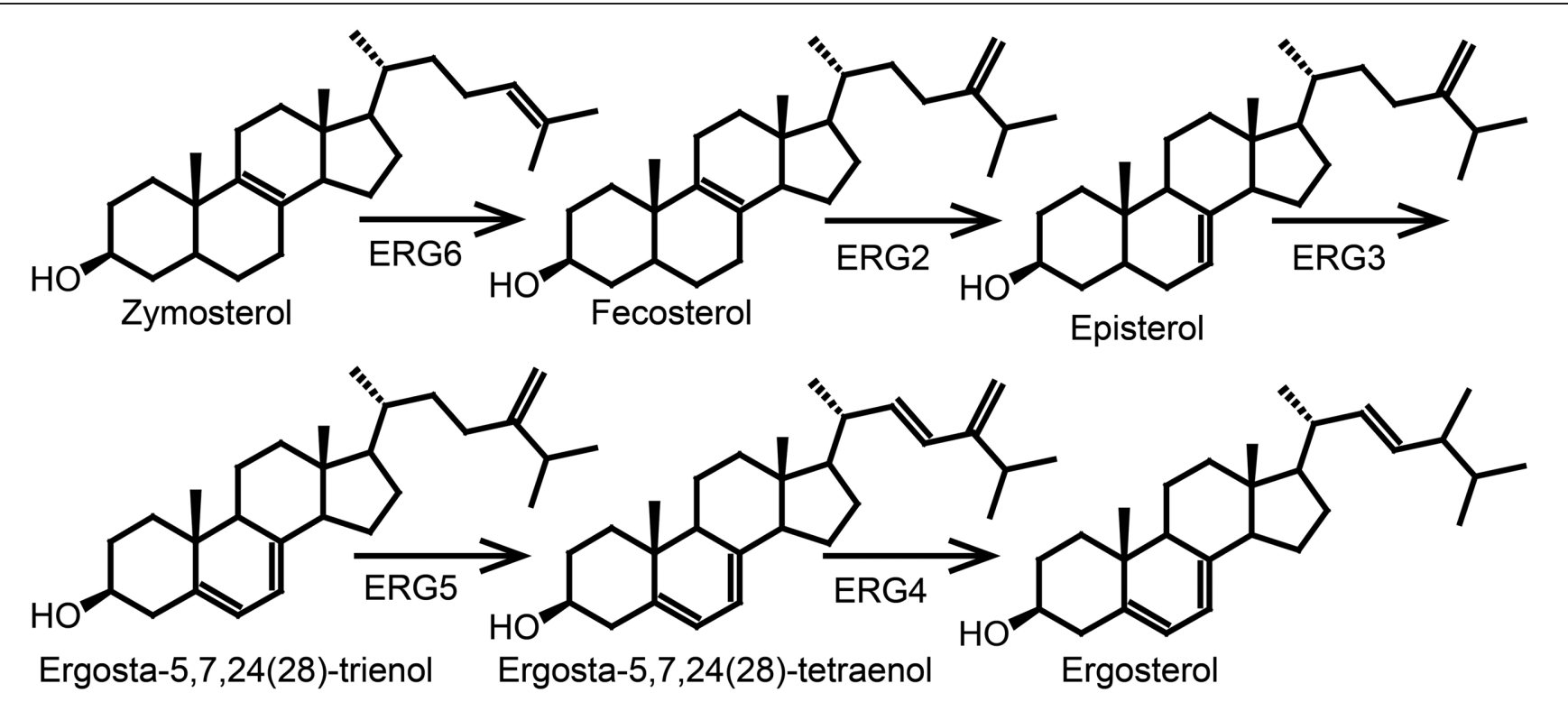

FIGURE 7 | The last five steps of the ergosterol biosynthetic pathway in Saccharomyces cerevis. ERG6, S-adenosylmethionine sterol methyltransferase; ERG2, C8-C7 sterol isomerase; ERG3, $\Delta^{5}$-desaturase; ERG5, $\Delta^{22}$-desaturase; ERG4, $\Delta^{24}$-reductase. Figure adapted from Lees et al. (1995).

a by-pass of SMT1. Thus, manipulation of SMT1 might be a tool to increase the 7-dehydrocholesterol and cholesterol content in plants.

\section{Proposed steps of the 24-desmethylsterol biosynthesis}

Several enzymes involved in the sterol biosynthesis can be found across plants and animals, e.g., $\Delta^{5,7}$-sterol- $\Delta^{7}$-reductase called DWARF5 in plants and 7-dehydrocholesterol reductase in animals. Several of these enzymes do not have absolute substrate specificity (Benveniste, 1986). The possibility, therefore, exist that plant biosynthetic enzymes could be involved in 24desmethyl sterol biosynthesis. Application of cycloartanol to growing tobacco plants generates cholesterol (Devys et al., 1969) and we hypothesize that the reduction of the $\Delta 24$ double bond of cycloartenol to yield cycloartanol is the first step of cholesterol synthesis in plants (Figure 8). In Arabidopsis, the $\Delta 24$-reduction step is catalyzed by $\Delta 5$-sterol- $\Delta 24$-reductase (DIM/DWARF1) (Klahre et al., 1998). Interestingly, the Arabidopsis dim mutant (Klahre et al., 1998) and also the rice dim mutant has decreased levels of cholesterol compared to the wild type (Hong et al., 2005). These results indicate a role of DIM/DWARF1 in cholesterol biosynthesis. Production of 7-dehydrocholesterol in animals involves a $\Delta^{7}$-sterol-C-5-desaturase (lathosterol 5-desaturase) that introduces a double bond at C5 (Figure 6). A similar $\Delta^{7}$-sterol-C-5-desaturase (DWARF7/STE1) exists in plants, which converts episterol/avanesterol into 5-dehydroepisterol/5dehydroavanesterol by a removal of two protons (Figure 8). An Arabidopsis mutant (ste1/dwarf7) defective in the $\Delta^{7}$-sterolC-5-desaturase has been identified, which only produces limiting amounts of $\Delta^{5,7}$-sterols (Gachotte et al., 1995, 2002; Choe et al., 1999; Husselstein et al., 1999). It can be hypothesized that a ste1/dwarf7 mutant would be defective in converting cholesta-7-enol to 7-dehydrocholesterol and further to cholesterol (Figure 8). However, no significant decrease in cholesterol levels was observed in ste1 mutants (Gachotte et al., 1995; Husselstein et al., 1999). The enzymatic step after C5 reduction is mediated by a $\Delta^{5,7}$-sterol- $\Delta^{7}$-reductase called DWARF5 in plants (Figure 8) and 7-dehydrocholesterol reductase in animals (Figure 6). DWARF5 e.g., catalyze the reduction of the $\Delta 7$ double bond in 5-dehydroepisterol to give the $\Delta 5$ sterol 24-methylenecholesterol (Choe et al., 2000). We propose that DWARF5 also act on 7-dehydrocholesterol to form cholesterol in plants (Figure 8). An Arabidopsis dwarf5 mutant accumulating $\Delta^{5,7}$-sterols has been identified (Choe et al., 2000). The DWARF5 mutant display a characteristic dwarf phenotype, which includes short robust stems, reduced fertility, prolonged life cycle and dark-green curled leaves when grown in light (Choe et al., 1999). The special dwarf phenotype is explained by a deficiency in brassinosteroids, which are important growth hormones for plants (Klahre et al., 1998; Choe et al., 1999, 2000; Hong et al., 2005). It is possible that vitamin $D_{3}$ producing plants have a less efficient DWARF5 enzyme that allows for accumulation of 7-dehydrocholesterol and later vitamin $\mathrm{D}_{3}$ by photoconversion.

\section{OCCURRENCE OF VITAMIN $D_{3}$ AND ITS METABOLITES IN PLANTS \\ PROVITAMIN $D_{3}$ AND VITAMIN $D_{3}$}

Vitamin $\mathrm{D}_{3}$ and its provitamin 7-dehydrocholesterol have been identified in the leaves of several plant species mostly belonging to Solanaceae (Esparza et al., 1982; Prema and Raghuramulu, 1994, 1996; Aburjai et al., 1998; Curino et al., 1998; Skliar et al., 2000) (Table 1). Huge variations exist in the content of vitamin $\mathrm{D}_{3}$ and 7-dehydrocholesterol (Table 1). Some studies used plant cell cultures instead of whole plants (Aburjai et al., 1996; Curino et al., 1998, 2001; Skliar et al., 2000), which may explain some 


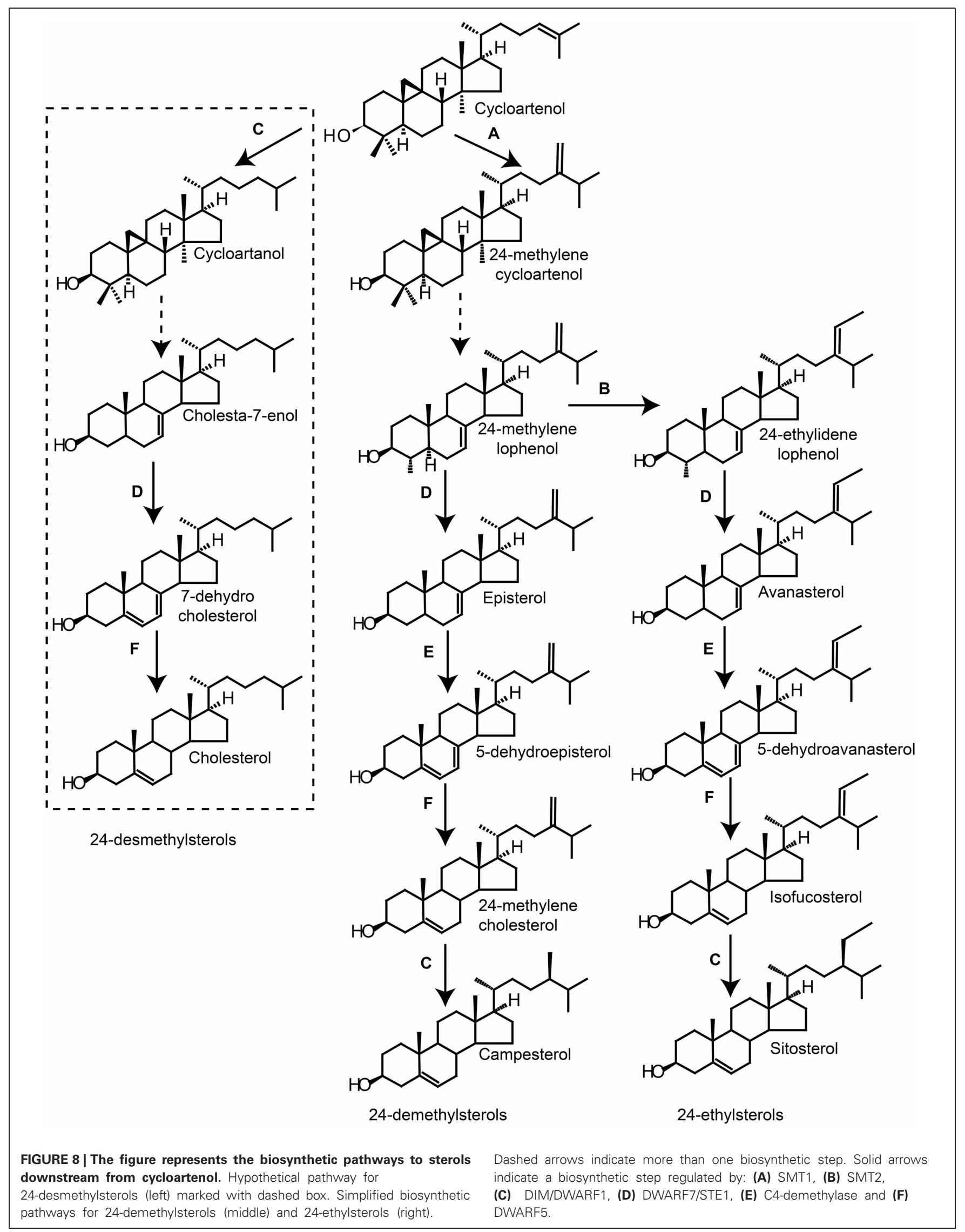


Table 1 | Content of vitamin $D_{3}$ and provitamin $D_{3}(\mu \mathrm{g} / \mathrm{g})$ in various plants determined with chemical methods.

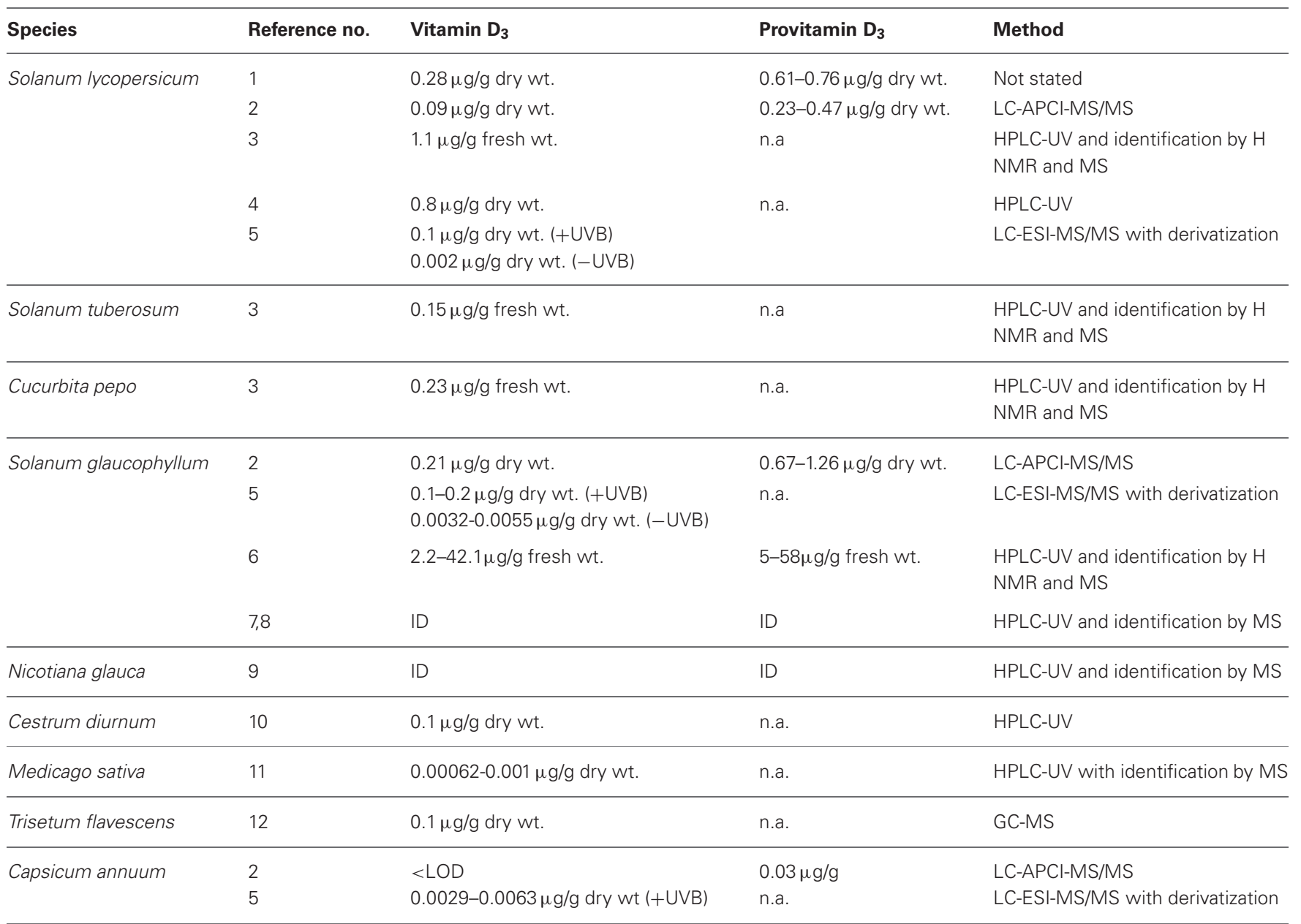

n.a., not analysed; ID, identified not quantified; $<L O D$, below detection limit.

1, (Björn and Wang, 2001); 2, (Jäpelt et al., 2011 b); 3, (Aburjai et al., 1998); 4, (Prema and Raghuramulu, 1996); 5, (Jäpelt et al., 2012); 6, (Aburjai et al., 1996); 7, (Curino et al., 2001); 8, (Curino et al., 1998); 9, (Skliar et al., 2000); 10, (Prema and Raghuramulu, 1994); 11, (Horst et al., 1984); 12, (Rambeck et al., 1979).

of the variability between studies. Growth conditions are easily controlled when using plant cells, but discrepancies between in vitro and in vivo can be seen due to transformations occurring in the culture medium (Curino et al., 2001). Differences in growth conditions, e.g., the intensity of the light source and length of exposure will have a significant impact on the vitamin $\mathrm{D}_{3}$ content, but unfortunately growth conditions are poorly described in most studies (Prema and Raghuramulu, 1994, 1996; Aburjai et al., 1998). However, vitamin $\mathrm{D}_{3}$ has been studied in S. lycopersicum grown in greenhouse with or without UVB exposure (Björn and Wang, 2001) and in S. lycopersicum, S. glaucophyllum and C. annuum using growth chambers, an UVB lamp and controlled temperature and light/day settings (Jäpelt et al., 2011b, 2012). Vitamin $\mathrm{D}_{3}$ has in most studies been identified after UVB exposure (Zucker et al., 1980; Aburjai et al., 1996; Björn and Wang, 2001; Jäpelt et al., 2011b), but vitamin $D_{3}$ synthesis without the action of UVB has also been reported (Curino et al., 1998; Jäpelt et al., 2012). Recently, we compared vitamin $\mathrm{D}_{3}$ in UVB- and non-UVB-exposed plants using a sensitive liquid chromatography electrospray ionization tandem mass spectrometry (LC-ESI-MS/MS) method. The content of vitamin $\mathrm{D}_{3}$ in the UVB-exposed plants was 18-64 times higher than for the non-UVB-exposed plants (Jäpelt et al., 2012). Previously failure to detect vitamin $\mathrm{D}_{3}$ in non-UVB-exposed plants could be due to the use of relative insensitive analytical methods. Since the isomerization of previtamin $\mathrm{D}_{3}$ to vitamin $\mathrm{D}_{3}$ is a temperature-dependent reaction an effect of growth temperature could be expected. Therefore, the effect of elevated temperature and a combination of elevated temperature and UVB light were investigated in S. lycopersicum, S. glaucophyllum and C. annuum (Jäpelt et al., 2012). Plants were kept in a growth chambers for 7 days at $32^{\circ} \mathrm{C}$ either exposed to UVB light or not, but no consistent effect was seen. In S. glaucophyllum the value for elevated temperatures combined with UVB was half the value for UVB alone, whereas in S. lycopersicum and C. annuum a small increase for elevated temperatures combined with UVB compared to UVB alone was observed (Jäpelt et al., 2012). 


\section{HYDROXYLATED METABOLITES OF VITAMIN $D_{3}$}

Hydroxylated metabolites of vitamin $\mathrm{D}_{3}$ have been found in various plants (Table 2). The highest content of $1,25(\mathrm{OH})_{2} \mathrm{D}_{3}$ has been found in S. glaucophyllum and not only in the leaves, but also in fruits, stems and roots (Weissenberg et al., 1989; Curino et al., 2001). The level of $1,25(\mathrm{OH})_{2} \mathrm{D}_{3}$ found in cell cultures varied according to the origin of the culture, i.e., stem $>$ leaf $>$ fruit (Curino et al., 2001). However, vitamin D like activity could not been found in tomatoes (Prema and Raghuramulu, 1996). Earlier work using cell cultures indicates that the production of hydroxylated metabolites is influenced by the calcium concentration (Aburjai et al., 1997; Curino et al., 2001; Burlini et al., 2002). The level of $25 \mathrm{OHD}_{3}$ (Aburjai et al., 1997) and $1,25(\mathrm{OH})_{2} \mathrm{D}_{3}$ (Burlini et al., 2002) in S. glaucophyllum cell suspensions increased markedly when incubated in a $\mathrm{Ca}^{2+}$ free media compared to if $\mathrm{Ca}^{2+}$ was present. However, another study performed with S. glaucophyllum cells showed that media deprived from calcium contained low levels of $1,25(\mathrm{OH})_{2} \mathrm{D}_{3}$ (Curino et al., 2001).

The biosynthesis of $1,25(\mathrm{OH})_{2} \mathrm{D}_{3}$ is finely regulated in vertebrates and the question is if this also is the case in plants. The $25 \mathrm{OHD}_{3} / 1,25(\mathrm{OH})_{2} \mathrm{D}_{3}$ ratio has either been reported to be $>1$ (Prema and Raghuramulu, 1994, 1996), 1 (Jäpelt et al., 2012) or $<1$ (Aburjai et al., 1996). This indicates that the conversion of $25 \mathrm{OHD}_{3}$ to $1,25(\mathrm{OH})_{2} \mathrm{D}_{3}$ not is as tightly regulated as in vertebrates. Enzymatic activities involved in formation of $25 \mathrm{OHD}_{3}$ and $1,25(\mathrm{OH})_{2} \mathrm{D}_{3}$ have been identified in S. glaucophyllum (Esparza et al., 1982). Vitamin D 25-hydroxylase activity has been localized in the microsomes, whereas the $1 \alpha$ hydroxylase activity has been localized in mitochondria and microsomes (Esparza et al., 1982). However, no enzymes have been isolated from plants showing vitamin D 25-hydroxylase or $1 \alpha$-hydroxylase catalytic activity. For the biological role of vitamin $\mathrm{D}_{3}$ and its hydroxylated metabolites in plant physiology is referred to Boland et al. (2003).

\section{VITAMIN $D_{3}$ CONJUGATES}

Several studies of S. glaucophyllum identified $1,25(\mathrm{OH})_{2} \mathrm{D}_{3}$ after enzymatic hydrolysis with glycosidases (Haussler et al., 1976; Wasserman et al., 1976b; Hughes et al., 1977; Napoli et al., 1977; Esparza et al., 1982; Jäpelt et al., 2012) and also in C. diurnum (Hughes et al., 1977). Similarly, vitamin $\mathrm{D}_{3}$ and $25 \mathrm{OHD}_{3}$ were identified in S. glaucophyllum after incubation with glycosidases (Esparza et al., 1982). Ruminal fluids contain glycosidases and research show that aqueous extracts of S. glaucophyllum leaves incubated with bovine ruminal fluid (de Boland et al., 1978) and ovine ruminal fluid (Esparza et al., 1983) exhibit more vitamin $\mathrm{D}$ activity than extracts not incubated. Later vitamin $\mathrm{D}_{3}$ and its metabolites were identified in S. glaucophyllum extracts incubated with ovine ruminal fluid (Skliar et al., 1992). These studies indicate that vitamin $\mathrm{D}_{3}$ and its metabolites exist as glycosides in plants. However, the existence of glycosides is debated and other

Table 2 | Content of the hydroxylated metabolites of vitamin $D_{3}$ in various plants determined by immunoassays or chemical methods.

\begin{tabular}{|c|c|c|c|c|c|}
\hline Species & $\begin{array}{l}\text { Reference } \\
\text { no. }\end{array}$ & $25 \mathrm{OHD}_{3}$ & Method & $1,25(\mathrm{OH})_{2} \mathrm{D}_{3}$ & Method \\
\hline \multirow{2}{*}{$\begin{array}{l}\text { Solanum } \\
\text { lycopersicum }\end{array}$} & 1 & $0.15 \mu \mathrm{g} / \mathrm{g}$ fresh wt. & HPLC-UV and MS identification & $<\mathrm{LOD}$ & HPLC-UV \\
\hline & 3 & $0.004 \mu \mathrm{g} / \mathrm{g}$ dry wt & LC-ESI-MS/MS with derivatization & $<L O D$ & $\begin{array}{l}\text { LC-ESI-MS/MS with } \\
\text { derivatization }\end{array}$ \\
\hline \multirow[t]{3}{*}{$\begin{array}{l}\text { Solanum } \\
\text { glaucophyllum }\end{array}$} & 3 & $0.011-0.031 \mu \mathrm{g} / \mathrm{g}$ dry wt & LC-ESI-MS/MS with derivatization & $0.012-0.032 \mu \mathrm{g} / \mathrm{g}$ dry wt & $\begin{array}{l}\text { LC-ESI-MS/MS with } \\
\text { derivatization }\end{array}$ \\
\hline & 4 & ID & HPLC-UV and MS identification & ID & $\begin{array}{l}\text { Radioreceptor assay, HPLC- } \\
\text { UV and MS identification }\end{array}$ \\
\hline & 5 & $1.0 \mu \mathrm{g} / \mathrm{g}$ fresh wt. & $\begin{array}{l}\text { HPLC-UV and MS and HNMR } \\
\text { identification }\end{array}$ & $0.1 \mu \mathrm{g} / \mathrm{g}$ fresh wt. & $\begin{array}{l}\text { HPLC-UV and MS and } \\
\text { HNMR identification }\end{array}$ \\
\hline $\begin{array}{l}\text { Cestrum } \\
\text { diurnum }\end{array}$ & 6 & $0.102 \mu \mathrm{g} / \mathrm{g}$ dry wt. & HPLC-UV and biological activity & $1 \mu \mathrm{g} / \mathrm{g}$ dry wt. & $\begin{array}{l}\text { HPLC-UV and biological } \\
\text { activity }\end{array}$ \\
\hline $\begin{array}{l}\text { Nicotiana } \\
\text { glauca }\end{array}$ & 7 & ID & HPLC-UV with MS identification & $0.3-1 \mu \mathrm{g} / \mathrm{g}$ fresh wt. & $\begin{array}{l}\text { Radioreceptor assay, HPLC- } \\
\text { UV and MS identification }\end{array}$ \\
\hline
\end{tabular}

ID, identified not quantified; $\angle L O D$, below detection limit.

1, (Aburjai et al., 1998); 2, (Prema and Raghuramulu, 1996); 3, (Jäpelt et al., 2012); 4, (Curino et al., 1998); 5, (Aburjai et al., 1996); 6, (Prema and Raghuramulu, 1994); 7. (Skliar et al., 2000). 
studies only quantified the free forms (Prema and Raghuramulu, 1994, 1996; Aburjai et al., 1996, 1997, 1998). It has been proposed that the glycoside content depends on the collection, drying and storage of the plant material, which may explain some differences between studies (Peterlik et al., 1977; Prema and Raghuramulu, 1994).

The site of glycosylation, the type of bond and the identity of the sugar unit have not been completely determined. The number of sugar units seems to differ as the vitamin D active glycosides of S. glaucophyllum and T. flavescens are soluble in water (Humphreys, 1973; Uribe et al., 1974; Wasserman et al., 1976b; Napoli et al., 1977; Morris and Levack, 1982), whereas the glycoside of $C$. diurnum are soluble in a mixture of chloroform and methanol (Wasserman et al., 1976a). Vidal et al. (1985) isolated the $1,25(\mathrm{OH})_{2} \mathrm{D}_{3}$ glycoside from S. glaucophyllum and found that $1,25(\mathrm{OH})_{2} \mathrm{D}_{3}$ was bound to a series of fructoglucosides of variable molecular weights.

The formation of glycosides may cause dramatic changes in the chemical, nutritional and metabolic properties (Gregory, 1998). Rambeck et al. (1984) studied the biological activity of $1 \alpha(\mathrm{OH}) \mathrm{D}_{3}$ 3- $\beta$-cellobioside, $1 \alpha(\mathrm{OH}) \mathrm{D}_{3} 3$ - $\beta$-glucoside and vitamin $\mathrm{D}_{3} 3-\beta$ glucoside and the corresponding parent molecules in bioassays using rats, chickens and quails. Glucosidation did not reduce the activity of the parent vitamin D (Rambeck et al., 1984). In constrast the $\beta$-D-glucoside of $1 \alpha(\mathrm{OH}) \mathrm{D}_{3}$ exhibited only $10 \%$ activity compared to $1 \alpha(\mathrm{OH})_{2} \mathrm{D}_{3}$ in all bioassays and the disaccharide $\left(1 \alpha(\mathrm{OH})\right.$ vitamin $\mathrm{D}_{3} 3$ - $\beta$-cellobioside) showed no vitamin $\mathrm{D}$ activity in the chicken bioassay (Rambeck et al., 1984). No study on glycosylated forms of $25 \mathrm{OHD}_{3}$ or $1,25(\mathrm{OH})_{2} \mathrm{D}_{3}$ has been performed. The existence of esters of vitamin $\mathrm{D}$ and the hydroxylated metabolites in plant material seems likely, but has not been shown.

\section{VITAMIN D 2 IN PLANT MATERIAL}

Ergosterol is a cell membrane component of fungi, but is also the provitamin of vitamin $\mathrm{D}_{2}$. Thus, vitamin $\mathrm{D}_{2}$ can be found in plants contaminated with fungi. Conversion to vitamin $\mathrm{D}_{2}$ occurs by sun-exposure of the plant material during growth and in the curing process. The antirachitic activity of grass and hay was studied intensively 50-80 years back using rat assays (Steenbock et al., 1925; Russell, 1929; Wallis, 1938, 1939; Moore et al., 1948; Newlander, 1948; Thomas and Moore, 1951; Newlander and Riddell, 1952; Thomas, 1952; Keener, 1954; Henry et al., 1958; Wallis et al., 1958). Most of these studies were on alfalfa (Medicago sativa L.) and the activities ranged from 0-3800 IU/kg, equivalent to 0-95 $\mu \mathrm{g}$ vitamin $\mathrm{D} / \mathrm{kg}$. However, some studies were on hay and others on fresh grass and dry matter was not stated in all cases, which makes comparisons difficult. The assumption at that time was that the antirachitic activity was due to vitamin $\mathrm{D}_{2}$ produced from ergosterol (Newlander and Riddell, 1952). Later vitamin $D_{2}$ was identified in crops using chemical methods (Horst et al., 1984; Jäpelt et al., 2011a). Horst et al. (1984) analyzed sun-cured field grown alfalfa using high performance liquid chromatography (HPLC) with UV detection and found $48 \mu \mathrm{g}$ vitamin $\mathrm{D}_{2} / \mathrm{kg}$. Jäpelt et al. (2011a) studied ergosterol and vitamin $\mathrm{D}_{2}$ in six varieties of perennial ryegrass (Lolium perenne L.) harvested four times during the season. The content of vitamin $\mathrm{D}_{2}$ and ergosterol was analyzed by LC atmospheric pressure chemical ionization tandem mass spectrometry (LC-APCI-MS/MS). An average content of vitamin $\mathrm{D}_{2}$ of $2 \mu \mathrm{g} / \mathrm{kg}$ fresh weight $(0.07-6.4 \mu \mathrm{g} / \mathrm{kg}$ fresh weight) was found (Jäpelt et al., 2011a). The vitamin $\mathrm{D}_{2}$ content was maximum $2 \%$ of the ergosterol content (Jäpelt et al., 2011a). The vitamin $\mathrm{D}_{2}$ content in these two studies is almost similar if we take into account the difference in dry matter between hay and fresh grass. Compared to results obtained by rat assays, the latter is slightly higher, which could be due the contribution of other vitamin $\mathrm{D}$ metabolites, or to a natural decline during the last 50-80 years.

The content of vitamin $\mathrm{D}_{2}$ in the plant material has been shown to increase with the level of sun exposure, and for crops also curing method (Hess and Weinstock, 1924; Steenbock et al., 1925; Russell, 1929; Newlander and Riddell, 1952). However, inconsistent results were obtained regarding the importance of sun exposure, which indicates that other factors may be important (Moore et al., 1948; Newlander, 1948; Henry et al., 1958; Wallis et al., 1958). Several studies observed that plants at later stage of maturity were higher in vitamin D than at early stage (Thomas and Moore, 1951; Keener, 1954; Henry et al., 1958). Especially, dead leaves were high in vitamin D and the proportion of dead leaves was observed to increase with maturity of the plant (Thomas and Moore, 1951). Newell et al. (1996) measured the ergosterol content in grass and found that it increased with time and with increasing fungal damage. Consequently, larger vitamin $\mathrm{D}$ activities are observed with time if the plant is exposed to sunlight. Recently, a systematic study looking at vitamin $D_{2}$ and ergosterol in perennial ryegrass during the season was performed (Jäpelt et al., 2011a). The content of both ergosterol and vitamin $\mathrm{D}_{2}$ changed more than a factor of 10 during the season (Jäpelt et al., 2011a). Weather factors were recorded and a principal component analysis (PCA) was performed to study, which factors that were important for the formation of vitamin $\mathrm{D}_{2}$. The PCA revealed that both sun/temperature and ergosterol/precipitation was important. This suggested that a combination of weather factors was involved as observed previously (Moore et al., 1948; Newlander, 1948; Henry et al., 1958; Wallis et al., 1958). Precipitation and high humidity are essential for ergosterol synthesis, whereas sunlight is necessary for vitamin $\mathrm{D}_{2}$ synthesis (Jäpelt et al., 2011a).

\section{VITAMIN D IN ALGAE}

Fish are known to be rich sources of vitamin $D_{3}$, but the origin of vitamin $\mathrm{D}_{3}$ in fish has not been clarified. Both a non-photochemical pathway and a photochemical pathway for vitamin $\mathrm{D}_{3}$ synthesis in fish are doubted (Mattila et al., 1997). The latter due to limited UVB-light in their natural habitats combined with low amounts of 7-dehydrocholesterol in fish skin (Bills, 1927; Sugisaki et al., 1974; Takeuchi et al., 1991; Sunita Rao and Raghuramulu, 1996b; Rao and Raghuramulu, 1997). Evidence, on the other hand, exist that microalgae as the basis of the food chain is the origin of the high content of vitamin $\mathrm{D}_{3}$ in fish (Takeuchi et al., 1991; Sunita Rao and Raghuramulu, 1996a). However, data for vitamin D in algae are limited and not consistent (De Roeck-Holtzhauer et al., 1991; Takeuchi et al., 
1991; Sunita Rao and Raghuramulu, 1996a; Brown et al., 1999). Takeuchi et al. (1991) found significant amounts of vitamin $\mathrm{D}_{2}(1.9-4.3 \mu \mathrm{g} / 100 \mathrm{~g})$, vitamin $\mathrm{D}_{3}(5.0-15 \mu \mathrm{g} / 100 \mathrm{~g})$ and their provitamins $(260-1450 \mu \mathrm{g} / 100 \mathrm{~g})$ in microalgae. Sunita Rao and Raghuramulu (1996a) also reported high concentrations of ergosterol $(390 \mu \mathrm{g} / 100 \mathrm{~g}), 7$-dehydrocholesterol $(2400 \mu \mathrm{g} / 100 \mathrm{~g})$, vita$\min \mathrm{D}_{2}(5.3 \mu \mathrm{g} / 100 \mathrm{~g})$ and vitamin $\mathrm{D}_{3}(80 \mu \mathrm{g} / 100 \mathrm{~g})$ in freshwater microalgae. The content of vitamin $\mathrm{D}_{2}$ and vitamin $\mathrm{D}_{3}$ in four Australian microalgae studied by Brown et al. (1999) were in all cases below the detection limit $(35 \mu \mathrm{g} / 100 \mathrm{~g})$ of the method used. De Roeck-Holtzhauer et al. (1991) studied vitamin $\mathrm{D}_{2}$ in several algae including the macroalgae Sargassum multicum and found very high amounts $(90-3900 \mu \mathrm{g} / 100 \mathrm{~g})$. No studies on vitamin $D_{3}$ in macroalage have been performed. Both vitamin $D_{2}$ and vitamin $\mathrm{D}_{3}$ are available for fish in their diet, but vitamin $\mathrm{D}_{2}$ is almost absent in fish (Lock et al., 2010). This suggests that the bioavailability of vitamin $\mathrm{D}_{2}$ is lower than for vitamin $\mathrm{D}_{3}$ (Andrews et al., 1980; Barnett et al., 1982; Takeuchi et al., 1991).

Microalgae usually live at the surface of the water and vitamin D is probably synthesized by sun exposure of provitamins D (Takeuchi et al., 1991). Takeuchi et al. (1991) observed that microalgae caught in August were higher in vitamin D than in October and December, which supports that vitamin D is synthesized from sun exposure of provitamin D. To synthesize vitamin $\mathrm{D}_{3}$ by $\mathrm{UVB}$ exposure, microalgae should be able to synthesize 7-dehydrocholesterol if using the same pathway as vertebrates. However, the sterols found in microalgae display a great diversity as may be expected from the large number of classes and species combined with a long evolutionary history (Volkman, 2003). Red algae (Rhodophyta) primarily contain cholesterol, although several species contain large amounts of desmosterol. Fucosterol is the dominant sterol of brown algae (Phaeophyta) (Patterson, 1971). Generalizations about the sterols in most other algae, e.g., diatoms (Bacillariophyta) and green algae (Chlorophyta) cannot be made as they are much more varied (Patterson, 1971). The most common sterol in diatoms are 24-methylcholesta-5,24(28)-dien-3 $\beta$-ol, but cholesterol and sitosterol are also common (Rampen et al., 2010). The green algae are very variable, they contain significantly amounts of 24ethyl sterols (Volkman, 2003), but also cholesterol and ergosterol (Patterson, 1974). Microalgae are an extremely diverse group, as also seen from the large variability in the sterol content. It is, therefore, difficult to make any conclusions about algae's production of vitamin $\mathrm{D}_{2}$ and vitamin $\mathrm{D}_{3}$. Species differences and geographic differences may be expected.

\section{ANALYTICAL METHODS TO STUDY THE VITAMIN D FORMS IN PLANTS}

Research into vitamin D in plants is limited, presumably due to limitations in selectivity and sensitivity of the analytical methods available. Determination of vitamin D in food has always been a challenge due to low amounts of vitamin $\mathrm{D}$ combined with the existence of multiple vitamin D active compounds. Plants are a complex matrix, which makes the analysis of vitamin $\mathrm{D}$ even more challenging. Selective and sensitive methods are, therefore, a prerequisite. Each step in the analytical methods used in the research of vitamin $\mathrm{D}$ in plants will be discussed in the following chapter.

\section{BIOLOGICAL METHODS FOR VITAMIN D}

The official method for vitamin D was for many years the line test using animals. Either a rat or a chicken was put on a vitamin $\mathrm{D}$ deficient diet until the animal developed rickets. Afterwards, they were fed plants or plant extracts and it was estimated to which extent the rickets were cured (Wallis, 1938, 1939; Moore et al., 1948; Thomas and Moore, 1951; Thomas, 1952; Keener, 1954; Henry et al., 1958; Wallis et al., 1958). This method is time-consuming as it takes 5 weeks, and precision and accuracy may be discussed. However, an advantage of this method may be that the amount of quantified vitamin $\mathrm{D}$ corresponds to the total vitamin $\mathrm{D}$ activity independent of the specific metabolites and their difference in activity. The interest in the $1,25(\mathrm{OH})_{2} \mathrm{D}$ metabolite initiated the use of more specific methods utilizing that a high strontium intake by chickens block the conversion of $25 \mathrm{OHD}$ to $1,25(\mathrm{OH})_{2} \mathrm{D}$ by suppressing $1 \alpha$-hydroxylase activity (Wasserman, 1974; Weissenberg et al., 1989). This means that the inhibitory effect of strontium can be overcome by the administration of $1,25(\mathrm{OH})_{2} \mathrm{D}$, but not by $25 \mathrm{OHD}$ and vitamin D. Studies of calcium absorption in nephrectomized rats that possess a suppressed $1 \alpha$-hydroxylase activity (Walling and Kimberg, 1975) and assays with organ-culture systems such as cultured duodenum have also been used to study $1,25(\mathrm{OH})_{2} \mathrm{D}$ specifically in plants (Corradino and Wasserman, 1974). However, the biological activity measured in these methods could be due to other compounds that interfere with vitamin D metabolism, calcium absorption or to other compounds present, e.g., calcium and phosphorus that increase or inhibit the activity of vitamin D. More specific methods are, therefore, needed to study vitamin D and its metabolites in details.

\section{CHEMICAL METHODS FOR VITAMIN D-SAMPLE PREPARATION}

Proper sample preparation is crucial for reliable analysis and should optimally release all vitamin D active compounds. Glycosylation and acetylation is general metabolic processes that occur in plants and vitamin D and related compounds are expected to be found as glycosides, esters and acetylated glycosides (Figure 3). Saponification followed by liquid-liquid extraction is typically used to liberate esters, where cold saponification is preferred over hot saponification due to reversible and temperature-dependent equilibration between vitamin $\mathrm{D}$ and pre-vitamin D (Buisman et al., 1968; Hanewald et al., 1968). However, saponification fails to hydrolyze the bond between vitamin $\mathrm{D}$ and the carbohydrate moiety in the glycosides. Both direct and indirect analysis (with or without hydrolysis) can be used for glycosides (Van Hoed et al., 2008). Direct analysis is fast, as a sample preparation step is omitted, but complicated as the needed conjugated standards is non-available. For indirect analyses, acid hydrolysis has been used to release glycosidic forms (Toivo et al., 2001; Liu et al., 2007; Nyström et al., 2007). Acid hydrolysis is typical performed under relatively harsh conditions, e.g., $60 \mathrm{~min}$ at $80^{\circ} \mathrm{C}$ with $6 \mathrm{M}$ ethanolic hydrochloric acid solution (Kamal-Eldin et al., 1998; Toivo et al., 2001; Nyström et al., 2007). This is not optimal due to risk 
of isomerization of certain sterols (Kamal-Eldin et al., 1998) including 5,7-dienes as 7-dehydrocholesterol (Dolle et al., 1988) as well as vitamin $\mathrm{D}_{3}$ (Jin et al., 2004). An alternative to acid hydrolysis is the gentler enzymatic hydrolysis. Kesselmeier et al. (1985) used $\beta$-glucosidase in the hydrolysis of steryl glycosides in oat leaves and seeds, but other researchers have not been successful in repeating these results (Moreau and Hicks, 2004; Nyström et al., 2008). A hypothesis is that the observation by Kesselmeier et al. (1985) may be due to impurities of minor enzymes rather than the actual $\beta$-glucosidase, whereas similar secondary activities not are present in modern highly purified enzyme preparations (Moreau and Hicks, 2004; Nyström et al., 2008).

The extraction of liberated vitamin D compounds from the non-saponifiable matter is usually performed by liquid/liquid extraction using non-polar organic solvents (CEN, 2008). Further clean-up of the extracts is usually needed to remove interfering compounds and to avoid contamination of the analytical column by other co-extracted substances, e.g. chlorophyll and other lipophilic pigments (Jäpelt et al., 2011b). Combinations of column chromatography or/and preparative HPLC have been used for purification of plant extracts before vitamin D analysis (Rambeck et al., 1979; Esparza et al., 1982; Morris and Levack, 1982; Prema and Raghuramulu, 1994; Curino et al., 1998, 2001; Skliar et al., 2000). However, fractionation by column chromatography is time-consuming and not suitable for routine analysis and has recently been replaced by solid phase extraction (SPE) (Jäpelt et al., 2011a,b).

If total vitamin $\mathrm{D}$ activity is required, the sum of vitamin $\mathrm{D}$ and any other metabolites that may have vitamin $\mathrm{D}$ activity must be quantified. The hydroxylated metabolites have higher polarity than vitamin $\mathrm{D}$, but despite the difference in polarity are vitamin D and 25OHD extracted in the same run (Mattila et al., 1995a; Jakobsen et al., 2004). Only few studies have included quantification of $1,25(\mathrm{OH})_{2} \mathrm{D}$ in food (Kunz et al., 1984; Takeuchi et al., 1988; Montgomery et al., 2000). These studies omitted the saponification step, which seems to question whether conjugated forms of $1,25(\mathrm{OH})_{2} \mathrm{D}$ will be quantified. Our recent study, included saponification in the analysis of $1,25(\mathrm{OH})_{2} \mathrm{D}$ in plant material, but poor extraction efficiency from the non-saponifiable matter was observed, which increased the detection limit (Jäpelt et al., 2012). Therefore, optimization of the extraction procedure is needed.

\section{QUANTIFICATION OF VITAMIN D FORMS}

An internal standard is essential for quantification of vitamin D due to reversible isomerization with the corresponding previtamin D (Schlatmann et al., 1964). An internal standard is also needed to eliminate analytical errors due to losses of vitamin D during sample preparation and to compensate for signal variation if using mass spectrometry (MS) detection (Dimartino, 2007). Vitamin $D_{2}$ and vitamin $D_{3}$ are chemically very similar and vitamin $\mathrm{D}_{2}$ has been used as internal standard when determining vitamin $\mathrm{D}_{3}$ and vice versa. However, this is not the best approach when vitamin $\mathrm{D}_{2}$ and vitamin $\mathrm{D}_{3}$ occur simultaneously as could be the case in plants (Horst et al., 1984). For quantification by MS isotopic labeled compounds are ideal internal standards, because of the complete resemblance with the analyte.

\section{SEPARATION AND DETECTION PRINCIPLES FOR VITAMIN D AND ITS STEROL PRECURSORS \\ Gas chromatography flame ionization detection (GC-FID) and gas chromatography mass spectrometry (GC-MS)}

Sterols act as precursors of vitamin D so sterol analysis is essential to investigate the biosynthesis of vitamin D in plants. Sterols are typically measured by gas chromatography (GC) as trimethylsilyl (TMS) ether derivates (Piironen et al., 2000), which are detected either by flame ionization detection (FID) (Phillips et al., 2005; Brufau et al., 2006; Liu et al., 2007) or MS (Toivo et al., 2001; Nyström et al., 2007). GC was also the first chromatography principle used to replace the biological assay for analysis of vitamin D (Bell and Christie, 1973), but while GC is a good separation method for sterols it is not the best choice for vitamin D. Vitamin D undergoes thermal cyclization in a GC split/splitless injector $\left(>125^{\circ} \mathrm{C}\right)$ resulting in formation of the corresponding pyro and isopyro compounds with a concomitant decrease in sensitivity (Yeung and Vouros, 1995). However, early studies did use GC for identification of vitamin $\mathrm{D}_{3}$ in plants (Rambeck et al., 1979; Suardi et al., 1994).

\section{High performance liquid chromatography with UV detection (HPLC-UV)}

HPLC with UV detection $(265 \mathrm{~nm})$ is used in official methods for vitamin D in food (Staffas and Nyman, 2003; CEN, 2008) and has also been used in recent studies on vitamin D in plants (Prema and Raghuramulu, 1994, 1996; Aburjai et al., 1996, 1997, 1998; Curino et al., 1998, 2001). Nevertheless, these methods are laborious as high degree of purification of the extracts is needed. Analysis of vitamin D in complex matrices such as plants is especially challenging due to co-eluting interferences.

GC is generally considered superior to HPLC for sterol analysis (Lagarda et al., 2006), but introduction of columns with particle sizes of $1-2 \mu \mathrm{m}$ improve resolution of co-eluting sterols and may bring HPLC ahead of GC (Lu et al., 2007). Furthermore, HPLC have compared to GC the advantage of analysis without derivatization and gentler conditions suitable for thermally unstable sterols. Even though HPLC may be combined with UV for detection of sterols (Careri et al., 2001; Sanchez-Machado et al., 2004), this is not the most sensitive method, as sterols adsorb UV between 200 and $210 \mathrm{~nm}$ where most organic solvents have low transparency.

\section{Liquid chromatography mass spectrometry (MS, LC-MS, LC-MS/MS)}

Detection of vitamin D by MS detection is challenging due to low ionization efficiency. The most used ionization source for LC-MS is ESI, which works best when the analyte already is in its ionic form in solution (Cech and Enke, 2001). The ionization efficiency of vitamin D and its sterol precursors are as a result low in most ESI methods (Dimartino, 2007). APCI is a much more efficient ionization technique for neutral and apolar substances such as vitamin D and has been used several times for vitamin D analysis (Dimartino, 2007; Byrdwell, 2009; Jäpelt et al., 2011b). Atmospheric pressure photoionization (APPI) is 
another ionization method suitable for lipophilic compounds, which also has been used for detection of vitamin D (Soldin et al., 2009). MS has been used for identification of vitamin $D_{3}$ in plants in several studies, but in most cases not coupled to liquid chromatography (LC) (Aburjai et al., 1996; Curino et al., 1998; Skliar et al., 2000). We recently used liquid chromatography tandem mass spectrometry (LC-MS/MS) for selective detection of vitamin D in various plant matrices (Jäpelt et al., 2011a,b). LC-MS/MS improves both selectivity and sensitivity compared to LC-MS in particular by using selected reaction monitoring (SRM). In SRM both a precursor and a product ion is selected, which reduce background noise resulting in a good signal to noise ratio. SRM increases selectivity, but more than one transition is needed for reliable confirmation, which preferable is combined with other evidence such as relative intensities of product ions in the mass spectra, accurate mass, retention time and peak shape to positively identify the compound as vitamin D (Jäpelt et al., 2011b). LC-MS and LC-MS/MS have also been used several times for analysis of sterols in plant matrices (Mezine et al., 2003; Rozenberg et al., 2003; Ruibal-Mendieta et al., 2004; Cañabate-Díaz et al., 2007; Lu et al., 2007; Jäpelt et al., 2011b). To study vitamin D and its sterol precursors in plants LC-MS/MS is the method of choice. However, a significant challenge is that the content of various sterols span several orders of magnitude. The major sterols such as sitosterol and campesterol is between 10 and $200 \mu \mathrm{g} / \mathrm{g}$ fresh weight, whereas minor sterols and vitamin $D_{3}$ are present at less than $0.1 \mu \mathrm{g} / \mathrm{g}$ fresh weight (Jäpelt et al., 2011b; Schrick et al., 2011). This requires a huge dynamic range of the analytical method or fractionation of the extracts.

\section{Nuclear magnetic resonance (NMR)}

Nuclear magnetic resonance (NMR) is a powerful tool for structure elucidation and identification and offer valuable information in addition to UV and MS detection. NMR can discriminate between compounds that only differ in terms of local chemical environment, e.g., compounds with same mass, but different locations of functional groups. However, in general NMR analyses require extensive purified samples, and possess low sensitivity (Eisenreich and Bacher, 2007). Nevertheless, ${ }^{1} \mathrm{H}$ NMR has been used for identification of vitamin $\mathrm{D}_{3}$ in plants, but extraction of as much as $2 \mathrm{~kg}$ fresh plant leaves was required (Aburjai et al., 1998).

\section{ANALYTICAL METHODS FOR OUANTIFICATION OF HYDROXYLATED METABOLITES OF VITAMIN D}

Analysis of the hydroxylated metabolites of vitamin D represents a challenge because they exist in even lower concentrations than vitamin D (Aburjai et al., 1996, 1998; Prema and Raghuramulu, 1996). They have been detected in plants using both proteinbinding assays (Skliar et al., 2000; Curino et al., 2001) and chemical methods such as HPLC with UV detection (Aburjai et al., 1998, 1996; Prema and Raghuramulu, 1994, 1996) and MS detection (Jäpelt et al., 2012). Protein-binding assays, including RIA (radioimmunoassay) and RRA (radioreceptor binding assay), are widely used in clinical laboratories for analysis of $25 \mathrm{OHD}$ and $1,25(\mathrm{OH})_{2} \mathrm{D}$ in serum due to the simplicity (Hollis and Horst, 2007). RIAs are commercially available and have been used for extracts and cell cultures of S. glaucophyllum and C. diurnum (Weissenberg et al., 1988; Gil et al., 2007). RRA has been applied for identification of $1,25(\mathrm{OH})_{2} \mathrm{D}_{3}$ in S. glaucophyllum (Curino et al., 2001) and Nicotiana glauca Graham (Skliar et al., 2000). However, the lipophilic nature of vitamin D makes it difficult to analyze in any protein-binding assay due to solubility problems (Hollis and Horst, 2007). Matrix effects are also common due to interfering compounds found in the assay tube but not in the standard that compete with binding to the protein. The most common chemical detection principle used for the detection of the hydroxylated metabolites in plants has been HPLC-UV, but this is not totally specific. Specific quantification of vitamin D metabolites can on the other hand be obtained by using MS methods. However, direct LC-MS/MS analysis of especially $1,25(\mathrm{OH})_{2} \mathrm{D}$ is challenging because of poor ionization efficiency, low concentration and an extensive product ion spectra by most soft ionization techniques (Aronov et al., 2008). Attempts to increase ionization efficiency have been reported several times mostly for serum samples, these include adduct formation (Kissmeyer and Sonne, 2001; Casetta et al., 2010), derivatization with Cookson-type reagents (Higashi and Shimada, 2004; Gao et al., 2005; Kamao et al., 2007; Aronov et al., 2008; Higashi et al., 2011) and microflow LC-MS together with derivatization (Duan et al., 2010). Microflow LC improve sensitivity 15-fold compared to normal LC, but has a small loading capacity that counteracts the sensitivity gain, especially when analyzing complex matrices (Duan et al., 2010). The advantage of using microflow LC may, therefore, be limited for analysis of plant extracts. Recently, LC-ESI-MS/MS in combination with Diels-Alder derivatization was used to study $25 \mathrm{OHD}_{3}$ and $1,25(\mathrm{OH})_{2} \mathrm{D}_{3}$ in the leaves of S. glaucophyllum, S. lycopersicum and C. annuum (Jäpelt et al., 2012).

\section{CONCLUDING REMARKS}

Vitamin D deficiency is a problem in populations with limited sun exposure where a dietary intake of vitamin $\mathrm{D}$ becomes essential. However, dietary recommendations for vitamin $\mathrm{D}$ are difficult to meet because few food items naturally contain vitamin $\mathrm{D}$ and it would, therefore, be valuable to increase the food sources of vitamin $\mathrm{D}$ in the human diet or to optimize the content by biofortification. Traditionally, only animal products have been considered a source of vitamin $\mathrm{D}_{3}$, but today we know that vitamin $\mathrm{D}_{3}$ and its metabolites are formed in certain plants. Accordingly, fruits and vegetables have the potential to serve as a source of vitamin D. Especially, the Solanaceae family contains high amounts of vitamin $\mathrm{D}_{3}$, which is of special interest considering the importance of this family in human nutrition. The Solanaceae family includes important vegetables such as potato, tomato and pepper all of which have been found to contain vitamin $\mathrm{D}_{3}$. Our current knowledge is limited to the content in leaves, but future investigation will elucidate if also the edible portions contain vitamin $D_{3}$. It would be valuable to screen a variety of crops and vegetables for vitamin $\mathrm{D}$, but to carry out a larger screening development of less time-consuming and preferably more sensitive analytical methods are needed. A further challenge is to improve methods to study and quantify vitamin $\mathrm{D}$ conjugates in details. 
Planktonic microalgae, inhabiting the sea, are another large group of photosynthetic organisms that contain vitamin D. Microalgae are, as part of the aquatic food chain, identified as a source of vitamin D for fish. Currently, the world's wild fish stocks are being overexploited and there has been a growth in the aqua-culture industry. The current trend is to replace fish meals or fish oil partly by vegetable feed substitutes when feeding cultured fish will reduce the content of vitamin D compared to wild fish (Bell and Waagbø, 2008). Microalgae with a high natural amount of vitamin D may be used as a natural vegetable form for the bio-fortification of aqua-cultured fish.

Basic knowledge about the biosynthesis of vitamin $\mathrm{D}_{3}$ in photosynthetic organisms is still lacking and any increase in our knowledge will help us to manipulate the content to produce plants with a higher natural amount of vitamin $D_{3}$. Vitamin $\mathrm{D}_{3}$ is only synthesized in minute amounts, which makes it challenging to study the pathways and enzymes involved. However, it also means that even small changes in vitamin $D_{3}$ can have a significant impact on human health. Biosynthesis of 24-desmethylsterols in plants is complex and poorly understood and makes the final goal to produce plants with a higher

\section{REFERENCES}

Aburjai, T., Al-Khalil, S., and Abuirjeie, M. (1998). Vitamin $\mathrm{D}_{3}$ and its metabolites in tomato, potato, egg plant and zucchini leaves. Phytochemistry 49, 2497-2499.

Aburjai, T., Bernasconi, S., Manzocchi, L. A., and Pelizzoni, F. (1997). Effect of calcium and cell immobilization on the production of cholecalciferol and its derivatives by Solanum malacoxylon cell cultures. Phytochemistry 46, 1015-1018.

Aburjai, T., Bernasconi, S., Manzocchi, L., and Pelizzoni, F. (1996). Isolation of 7-dehydrocholesterol from cell cultures of Solanum malacoxylon. Phytochemistry 43, 773-776.

Andrews, J. W., Murai, T., and Page, J. W. (1980). Effects of dietary cholecalciferol and ergocalciferol on catfish. Aquaculture 19, 49-54.

Armas, L. A. G., Hollis, B. W., and Heaney, R. P. (2004). Vitamin $\mathrm{D}_{2}$ is much less effective than vitamin $\mathrm{D}_{3}$ in humans. J. Clin. Endocrinol. Metab. 89, 5387-5391.

Arnqvist, L., Dutta, P. C., Jonsson, L., and Sitbon, F. (2003). Reduction of cholesterol and glycoalkaloid levels in transgenic potato plants by overexpression of a type 1 sterol methyltransferase cDNA. Plant Physiol. 131, 1792.

Aronov, P. A., Hall, L. M., Dettmer, K., Stephensen, C. B., and Hammock, B. D. (2008). Metabolic profiling of major vitamin D metabolites using Diels-Alder derivatization and ultra-performance liquid chromatography-tandem mass spectrometry. Anal. Bioanal. Chem. 391, 1917-1930.

Askew, F. A., Bourdillon, R. B., Bruce, H. M., Jenkins, R. G. C., and Webster, T. A. (1930). The distillation of vitamin D. Proc. R. Soc. Lond. B 107, 76 .

Bach, T. J., and Benveniste, P. (1997). Cloning of cDNAs or genes encoding enzymes of sterol biosynthesis from plants and other eukaryotes: heterologous expression and complementation analysis of mutations for functional characterization. Prog. Lipid Res. 36, 197-226.

Bae, S. H., and Paik, Y. K. (1997). Cholesterol biosynthesis from lanosterol: development of a novel of rat liver microsomal lanosterol delta 24-reductase. Biochem. J. 326, 609-615.

Bailey, R. L., Dodd, K. W., Goldman, J. A., Gahche, J. J., Dwyer, J. T., Moshfegh, A. J., et al. (2010). Estimation of total usual calcium and vitamin D intakes in the United States. J. Nutr. 140, 817-822.

Barnett, B. J., Cho, C. Y., and Slinger, S. J. (1982). Relative biopotency of dietary ergocalciferol and cholecalciferol and the role of and requirement for vitamin $\mathrm{D}$ in rainbow trout (Salmo gairdneri). J. Nutr. 112, 2011-2019.

Basudde, C. D. K., and Humphreys, D. J. (1976). The vitamin $\mathrm{D}_{3}$ metabolite-type activity of Solanum malacoxylon. Clin. Endocrinol. 5, 109-119.

Bell, J. G., and Christie, A. A. (1973). Gas-liquid chromatographic assay method and characterization

natural amount of vitamin $\mathrm{D}_{3}$ a great challenge. Currently, the key biosynthetic steps and the enzymes involved are unknown. These need to be identified before we even can begin to modify the content of vitamin $\mathrm{D}_{3}$ in plants. In the present review, a hypothetical biosynthetic pathway for 7-dehydrocholesterol and cholesterol is presented. The steps catalyzed by SMT1 and DWARF5 seem to be promising targets to manipulate the level of 7-dehydrocholesterol in plants. A block in SMT1 will force the biosynthetic pathway in the direction of 7-dehydrocholesterol and cholesterol. Further increase in 7-dehydrocholesterol can probably be achieved by a block in $\Delta^{5,7}$-sterol- $\Delta^{7}$-reductase (DWARF5). However, any increase in provitamin $\mathrm{D}_{3}$ should be viewed in the context of the overall changes in the metabolic profile and a significant challenge will be selective to accumulate vitamin $\mathrm{D}_{3}$ in edible organs such as fruits, without affecting plant growth and the development of the plant and consequently yields. An important thing to consider before putting a lot of energy into producing plants with a high amount of vitamin $\mathrm{D}$ is the bioavailability, as low bioavailability of vitamin $\mathrm{D}$ from plants may diminish the potential of plants as a new vitamin D source.

determination of vitamin $\mathrm{D}$ in cod-liver oil. Analyst 98, 268-273.

Bell, J. G. and Waagbø, R. (2008). "Safe and nutritious aquaculture produce: benefits and risks of alternative sustainable aquafeeds" in Aquaculture in the Ecosystem, eds M. Holmer, K. Black, C. M. Duarte, N. Marbá, and I. Karakassis (Springer), 185-225.

Benveniste, P. (1986). Sterol biosynthesis. Annu. Rev. Plant Physiol. 37, 275-308.

Benveniste, P. (2002). Sterol Metabolism. The Arabidopsis Book 1:e0004. doi: 10.1199/tab.0004

Benveniste, P. (2004). Biosynthesis and accumulation of sterols. Annu. Rev. Plant. Biol. 55, 429-457.

Bergenstråhle, A., Borgå, P., and Jonsson, L. (1996). Sterol composition and synthesis in potato tuber discs in relation to glycoalkaloid synthesis. Phytochemistry 41, 155-161.

Bhattacharyya, M. H., and DeLuca, H. F. (1973). The regulation of rat liver calciferol-25-hydroxylase. J. Biol. Chem. 248, 2969-2973.

Bills, C. E. (1927). The distribution of vitamin D with some notes on its possible origin. J. Biol. Chem. 72, 751-758.

Björn, L. O., and Wang, T. (2001). Is provitamin D a UV-B receptor in plants? Plant Ecol. 154, 1-8.

Bloch, K. E. (1983). Sterol, structure and membrane function. CRC Crit. Rev. Biochem. 14, 47-92.

Boland, R., Skliar, M., Curino, A., and Milanesi, L. (2003). Vitamin D compounds in plants. Plant Sci. 164, 357-369.
Boland, R. L. (1986). Plants as a source of vitamin $\mathrm{D}_{3}$ metabolites. Nutr. Rev. 44, 1-8.

Brot, C., Vestergaard, P., Kolthoff, N., Gram, J., Hermann, A. P., and Sørensen, O. H. (2001). Vitamin D status and its adequacy in healthy Danish perimenopausal women: relationships to dietary intake, sun exposure and serum parathyroid hormone. Br. J. Nutr. 86(Suppl. 1), S97-S103.

Brown, M., Mular, M., Miller, I., Farmer, C., and Trenerry, C. (1999). The vitamin content of microalgae used in aquaculture. J. Appl. Phycol. 11, 247-255.

Brufau, G., Codony, R., Canela, M. A., and Rafecas, M. (2006). Rapid and Quantitative Determination of Total Sterols of Plant and Animal Origin in Liver Samples by Gas Chromatography. Chromatographia 559-563.

Buisman, J. A., Hanewald, K. H. Mulder, F. J., Roborgh, J. R., and Keuning, K. J. (1968). Evaluation of the effect of isomerization on the chemical and biological assay of vitamin D. Analysis of fat-soluble vitamins X. J. Pharm. Sci. 57, 1326-1329.

Burlini, N., Bernasconi, S., and Manzocchi, L. A. (2002). Effects of elicitors and $\mathrm{Ca}^{2+}$ deprivation on the levels of sterols and $1 \alpha$, 25-dihydroxy vitamin $\mathrm{D}_{3}$ in cell cultures of Solanum malacoxylon. Funct. Plant Biol. 29, 527-533.

Byrdwell, W. C. (2009). Comparison of analysis of vitamin $\mathrm{D}_{3}$ in foods 
using ultraviolet and mass spectrometric detection. J. Agric. Food Chem. 57, 2135-2146.

Calvo, M. S., Whiting, S. J., and Barton, C. N. (2004). Vitamin D fortification in the United States and Canada: current status and data needs. Am. J. Clin. Nutr. 80, 1710S-1716S.

Cañabate-Díaz, B., Carretero, A. S., Fernández-Gutiérrez, A., Vega, A. B., Frenich, A. G., Vidal, J. L. M., et al. (2007). Separation and determination of sterols in olive oil by HPLC-MS. Food Chem. 102, 593-598.

Cantorna, M. T., and Mahon, B. D. (2004). Mounting evidence for vitamin $\mathrm{D}$ as an environmental factor affecting autoimmune disease prevalence. Exp. Biol. Med. 229, 1136-1142.

Careri, M., Elviri, L., and Mangia, A. (2001). Liquid chromatographyUV determination and liquid chromatography-atmospheric pressure chemical ionization mass spectrometric characterization of sitosterol and stigmasterol in soybean oil. J. Chromatogr. A 935, 249-257.

Casetta, B., Jans, I., Billen, J., Vanderschueren, D., and Bouillon, R. (2010). Development of a method for the quantification of $1,25(\mathrm{OH})_{2}$-vitamin $\mathrm{D}_{3}$ in serum by liquid chromatography tandem mass spectrometry without derivatization. Eur. J. Mass Spectrom. 16, 81-89.

Cashman, K. D., Seamans, K. M., Lucey, A. J., Stöcklin, E., Weber, P., Kiely, M., et al. (2012). Relative effectiveness of oral 25-hydroxyvitamin $\mathrm{D}_{3}$ and vitamin $\mathrm{D}_{3}$ in raising wintertime serum 25-hydroxyvitamin D in older adults. Am. J. Clin. Nutr. 95, 1350-1356.

Cech, N. B., and Enke, C. G. (2001). Practical Implications of Some Recent Studies in Electrospray Ionization Fundamentals. Mass Spectrom. Rev. 20, 362-387.

CEN, (2008). EN12821 Foodstuffs Determination of Vitamin D by High Performane Liquid Chromatography - Measurement of Cholecalciferol (D3) and Ergocalciferol (D2) (Bruxelles: European Committee for Standardization).

Choe, S., Noguchi, T., Fujioka, S., Takatsuto, S., Tissier, C. P., Gregory, B. D., et al. (1999). The Arabidopsis dwf7/stel mutant is defective in the $\delta 7$ Sterol C-5 desaturation step leading to brassinosteroid biosynthesis. Plant Cell 11, 207-222.

Choe, S., Tanaka, A., Noguchi, T., Fujioka, S., Takatsuto, S., Ross, A. S., et al. (2000). Lesions in the sterol $\Delta 7$ reductase gene of Arabidopsis cause dwarfism due to a block in brassinosteroid biosynthesis. Plant J. 21, 431-443.

Clausen, I., Jakobsen, J., Leth, T., and Ovesen, L. (2003). Vitamin $\mathrm{D}_{3}$ and 25-hydroxyvitamin $\mathrm{D}_{3} \mathrm{n}$ raw and cooked pork cuts. J. Food Comp. Anal. 16, 575-585.

Corradino, R. A., and Wasserman, R. H. (1974). 1, 25-dihydroxycholecalciferol-like activity of Solanum malacoxylon extract on calcium transport. Nature 252, 716-718.

Curino, A., Milanesi, L., Benassati, S., Skliar, M., and Boland, R. (2001). Effect of culture conditions on the synthesis of vitamin $\mathrm{D}_{3}$ metabolites in Solanum glaucophyllum grown in vitro. Phytochemistry 58, 81-89.

Curino, A., Skliar, M., and Boland, R. (1998). Identification of 7dehydrocholesterol, vitamin $\mathrm{D}_{3}, 25(\mathrm{OH})$-vitamin $\mathrm{D}_{3}$ and 1 , $25(\mathrm{OH})_{2}$-vitamin $\mathrm{D}_{3}$ in Solanum glaucophyllum cultures grown in absence of light. Biochim. Biophys. Acta 1425, 485-492.

Dallorso, M. E., Gil, S., Pawlak, E. Lema, F., and Marquez, A. (2008). 1, $25(\mathrm{OH}) 2$ vitamin $\mathrm{D}$ concentration in the plasma of Solanum glaucophyllum intoxicated rabbits. Aust. Vet. J. 79, 419-423.

Danish Food Composition Databank, revision. 7. (2008). Department of Nutrition, National Food Institute, Technical University of Denmark. Website: http://www.foodcomp.dk/. Retrieved March 2013.

Dawson-Hughes, B., Heaney, R. P. Holick, M. F., Lips, P., Meunier, P. J., and Vieth, R. (2005). Estimates of optimal vitamin D status. Osteoporos. Int. 16, 713-716.

de Boland, A. R., Skliar, M. I., Gallego, S., Esparza, M., and Boland, R. L. (1978). Potentiation of the effects of Solanum malacoxylon extracts on rat intestinal phosphate and calcium absorption by incubation with ruminal fluid. Calcif. Tissue Res. 26, 215-219.

De Roeck-Holtzhauer, Y., Quere, I., and Claire, C. (1991). Vitamin analysis of five planktonic microalgae and one macroalgae. J. Appl. Phycol. 3, 259-264.

DeLuca, H. F. (2004). Overview of general physiologic features and functions of vitamin D. Am. J. Clin. Nutr. 80, 1689S-1696S.

Devys, M., Alcaide, A., and Barbier, M. (1969). Biosynthesis of cholesterol from cycloartanol by the tobacco, Nicotiana tabacum. Bull. Soc. Chim. Biol. 51, 133.
Diener, A. C., Li, H., Zhou, W., Whoriskey, W. J., Nes, W. D., and Fink, G. R. (2000). Sterol methyltransferase 1 controls the level of cholesterol in plants. Plant Cell 12 , 853-870.

Dimartino, G. (2007). Convenient analysis of vitamin $\mathrm{D}$ in cheese and other food matrixes by liquid chromatography/mass spectrometry. J. AOAC Int. 90, 1340-1345.

Dinan, L. (2001). Phytoecdysteroids: biological aspects. Phytochemistry 57, 325-339.

Dolle, R. E., Schmidt, S. J., Eggleston, D., and Kruse, L. I. (1988). Studies on the acid-catalyzed homonuclear steroidal diene isomerization. J. Org. Chem. 53, 1563-1566.

Duan, X., Weinstock-Guttman, B., Wang, H., Bang, E., Li, J. Ramanathan, M., et al. (2010). Ultrasensitive quantification of serum vitamin D metabolites using selective solid-phase extraction coupled to microflow liquid chromatography and isotope-dilution mass spectrometry. Anal. Chem. 82 2488-2497.

Eisenreich, W., and Bacher, A. (2007) Advances of high-resolution NMR techniques in the structural and metabolic analysis of plant biochemistry. Phytochemistry 68 2799-2815.

Esparza, M. S., Skliar, M. I., Gallego, S. E., and Boland, R. L. (1983). Modification by rumen of hypercalcemic activity of Solanum malacoxylon on the chick embryo. Planto Med. 47, 63-64.

Esparza, M. S., Vega, M., and Boland, R. L. (1982). Synthesis and composition of vitamin $\mathrm{D}_{3}$ metabolites in Solanum malacoxylon. Biochim. Biophys. Acta 719, 633-640.

Gachotte, D., Husselstein, T., Bard, M., Lacroute, F., and Benveniste, P. (2002). Isolation and characterization of an Arabidopsis thaliana cDNA encoding a $\Delta 7$ sterol-C-5-desaturase by functional complementation of a defective yeast mutant. Plant J. 9, 391-398.

Gachotte, D., Meens, R., and Benveniste, P. (1995). An Arabidopsis mutant deficient in sterol biosynthesis: heterologous complementation by ERG3 encoding a $\Delta 7$-sterol-C-5-desaturase from yeast. Plant J. 8, 407-416.

Gao, S., Zhang, Z. P., and Karnes, H. T. (2005). Sensitivity enhancement in liquid chromatography/atmospheric pressure ionization mass spectrometry using derivatization and mobile phase additives. J. Chromatogr. B, 825, 98-110.
Gil, S., Dallorso, M., and Horst, R. (2007). Screening of vitamin D activity (VDA) of Solanum glaucophyllum leaves measured by radioimmunoassay (RIA). J. Steroid Biochem. Mol. Biol. 103, 483-486.

Graff, I. E., Høie, S., Totland, G. K., and Lie, Ø. (2002). Three different levels of dietary vitamin $\mathrm{D}_{3}$ fed to first-feeding fry of Atlantic salmon (Salmo salar L.): effect on growth, mortality, calcium content and bone formation. Aquacult. Nutr. 8, 103-111.

Gregory, J. F. III. (1998). Nutritional properties and significance of vitamin glycosides. Annu. Rev. Nutr. 18 277-296.

Hanewald, K. H., Mulder, F. J., and Keuning, K. J. (1968). Thin-layer chromatographic assay of vitamin $\mathrm{D}$ in high-potency preparations. Analysis of fat-soluble vitamins IX. J. Pharm. Sci. 57, 1308-1312.

Hartmann, M. A. (2004). Sterol metabolism and functions in higher plants. Lipid Metab. Membr. Biogenesis 6, 57-81.

Haussler, M. R., Wasserman, R. H., McCain, T. A., Peterlik, M., Bursac, K. M., and Hughes, M. R. (1976). 1 25-dihydroxyvitamin $\mathrm{D}_{3}$-glycoside: identification of a calcinogenic principle of Solanum malacoxylon. Life Sci. 18, 1049-1056.

Havinga, E. (1973). Vitamin, D, example and challenge. Cell. Mol. Life Sci. 29, 1181-1193.

Henry, K. M., Kon, S. K., Thompson, S. Y., McCallum, J. W., and Stewart, J. (1958). The vitamin D activity of pastures and hays. Br. J. Nutr. 12 462-469.

Hess, A. F., and Weinstock, M. (1924). Antirachitic properties imparted to inert fluids and to green vegetables by ultra-violet irradiation. J. Biol. Chem. 62, 301-313.

Hess, A. F., and Weinstock, M. (1925). A further report on imparting antirachitic properties to inert substances by ultra-violet irradiation. J. Biol. Chem. 63, 297-304.

Higashi, T., and Shimada, K. (2004) Derivatization of neutral steroids to enhance their detection characteristics in liquid chromatography-mass spectrometry. Anal. Bioanal. Chem. 378, 875-882.

Higashi, T., Suzuki, M., Hanai, J., Inagaki, S., Min, J. Z., Shimada, K., et al. (2011). A specific LC/ESI-MS/MS method for determination of 25-hydroxyvitamin $\mathrm{D}_{3}$ in neonatal dried blood spots containing a potential interfering metabolite 3-epi-25hydroxyvitamin $\mathrm{D}_{3}$. J. Sep. Sci. 34, 725-732. 
Hohman, E. E., Martin, B. R., Lachcik, P. J., Gordon, D. T., Fleet, J. C., and Weaver, C. M. (2011). Bioavailability and efficacy of vita$\min \mathrm{D}_{2}$ from UV-irradiated yeast in growing, vitamin D-deficient rats. J. Agric. Food Chem. 59, 2341-2346.

Holick, M. F. (2003). Vitamin D: a millenium perspective. J. Cell. Biochem. 88, 296-307.

Holick, M. F. (2004). Sunlight and vitamin $\mathrm{D}$ for bone health and prevention of autoimmune diseases, cancers, and cardiovascular disease. Am. J. Clin. Nutr. 80, 1678S-1688S.

Holick, M. F. (2011). Vitamin D: a Dlightful solution for health. J. Invest. Med. 59, 872-880.

Holick, M. F., Biancuzzo, R. M., Chen, T. C., Klein, E. K., Young, A., Bibuld, D., et al. (2008). Vitamin $D_{2}$ is as effective as vitamin $\mathrm{D}_{3}$ in maintaining circulating concentrations of 25-hydroxyvitamin D. J. Clin. Endocrinol. Metab. 93, 677-681.

Holick, M. F., MacLaughlin, J. A., and Doppelt, S. H. (1981). Regulation of cutaneous previtamin $\mathrm{D}_{3}$ photosynthesis in man: skin pigment is not an essential regulator. Science 211, 590-593.

Hollis, B. W., and Horst, R. L. (2007). The assessment of circulating $25(\mathrm{OH}) \mathrm{D}$ and $1,25(\mathrm{OH})_{2} \mathrm{D}$ : Where we are and where we are going. J. Steroid Biochem. Mol. Biol. 103, 473-476.

Holmberg, N., Harker, M., Gibbard, C. L., Wallace, A. D., Clayton, J. C., Rawlins, S., et al. (2002). Sterol C24 methyltransferase type 1 controls the flux of carbon into sterol biosynthesis in tobacco seed. Plant Physiol. 130, 303-311.

Hong, Z., Ueguchi-Tanaka, M., Fujioka, S., Takatsuto, S., Yoshida, S., Hasegawa, Y., et al. (2005). The rice brassinosteroid-deficient dwarf2 mutant, defective in the rice homolog of Arabidopsis DIMINUTO/DWARF1, is rescued by the endogenously accumulated alternative bioactive brassinosteroid, dolichosterone. Plant Cell 17, 2243-2254.

Horst, R. L., Reinhardt, T. A., Russell, J. R., and Napoli, J. L. (1984). The isolation and identification of vitamin $\mathrm{D}_{2}$ and vitamin $\mathrm{D}_{3}$ from Medicago sativa (alfalfa plant). Arch. Biochem. Biophys. 231, 67-71.

Hughes, M. R., McCain, T. A., Chang, S. Y., Haussler, M. R., Villareale, M., and Wasserman, R. H. (1977). Presence of 1, 25-dihydroxyvitamin $\mathrm{D}_{3}$-glycoside in the calcinogenic plant Cestrum diurnum. Nature 268, 347-349.
Humphreys, D. J. (1973). Studies on the active principle of Solanum malacoxylon. Nature 246, 155-157.

Husselstein, T., Schaller, H., Gachotte, D., and Benveniste, P. (1999). $\Delta 7$-sterol-C5-desaturase: molecular characterization and functional expression of wild-type and mutant alleles. Plant Mol. Biol. 39, 891-906.

Hyppönen, E., Läärä, E., Reunanen, A., Järvelin, M. R., and Virtanen, S. M. (2001). Intake of vitamin D and risk of type 1 diabetes: a birth-cohort study. Lancet 358, 1500-1503.

IOM (Institute of Medicine). (2011). Dietary Reference Intakes for Calcium and Vitamin D. Washington, DC: The National Academies Press, 8-10.

Jakobsen, J., and Saxholt, E. (2009). Vitamin D metabolites in bovine milk and butter. J. Food Comp. Anal. $22,472-478$.

Jakobsen, J. (2007). Bioavailability and bioactivity of vitamin D3 active compounds - Which potency should be used for 25hydroxyvitamin D3? Int. Congr. Ser. 1297, 133-142.

Jakobsen, J., Clausen, I., Leth, T., and Ovesen, L. (2004). A new method for the determination of vitamin $\mathrm{D}_{3}$ and 25-hydroxyvitamin $\mathrm{D}_{3}$ in meat. J. Food Comp. Anal. 17, 777-787.

Jakobsen, J., Maribo, H., Bysted, A. Sommer, H. M., and Hels, $\mathrm{O}$ (2007). 25-Hydroxyvitamin $\quad \mathrm{D}_{3}$ affects vitamin D status similar to vitamin $\mathrm{D}_{3}$ in pigs-but the meat produced has a lower content of vitamin D. Br. J. Nutr. 98, 908-913.

Jäpelt, R. B., Didion, T., Smedsgaard, J., and Jakobsen, J. (2011a). Seasonal variation of provitamin $\mathrm{D}_{2}$ and vitamin $\mathrm{D}_{2}$ in perennial ryegrass (Lolium perenne L.). J. Agric. Food Chem. 59, 10907-10912.

Jäpelt, R. B., Silvestro, D., Smedsgaard, J., Jensen, P. E., and Jakobsen, J. (2011b). LC-MS/MS with atmospheric pressure chemical ionization to study the effect of UV treatment on the formation of vitamin $\mathrm{D}_{3}$ and sterols in plants. Food Chem. 129, 217-225.

Jäpelt, R. B., Silvestro, D., Smedsgaard, J., Jensen, P. E., and Jakobsen, J. (2012). Quantification of vitamin $\mathrm{D}_{3}$ and its hydroxylated metabolites in waxy leaf nightshade (Solanum glaucophyllum Desf.), tomato (Solanum lycopersicum L.) and bell pepper (Capsicum annuum L.) Food Chem. 138, 1206-1211.

Jin, X., Yang, X., Yang, L., Liu, Z. L., and Zhang, F. (2004). Autoxidation of isotachysterol. Tetrahedron 60, 2881-2888.
Jones, G., Strugnell, S. A., and DeLuca, H. F. (1998). Current understanding of the molecular actions of vitamin D. Physiol. Rev. 78, 1193-1231.

Kamal-Eldin, A., Määttä, K., Toivo, J., Lampi, A. M., and Piironen, V. (1998). Acid-catalyzed isomerization of fucosterol and $\Delta 5$-avenasterol. Lipids 33 , 1073-1077.

Kamao, M., Tsugawa, N., Suhara, Y., Wada, A., Mori, T., Murata, K. et al. (2007). Quantification of fatsoluble vitamins in human breast milk by liquid chromatographytandem mass spectrometry. J. Chromatogr. B 859, 192-200.

Kandutsch, A., and Russell, A. (1960). Preputial gland tumor sterols III. A metabolic pathway from lanosterol to cholesterol. J. Biol. Chem. 235 2256-2261.

Keener, H. A. (1954). The effect of various factors on the vitamin D content of several common forages. J. Dairy Sci. 37, 1337-1345.

Kendrick, J., Targher, G., Smits, G., and Chonchol, M. (2009). 25Hydroxyvitamin D deficiency is independently associated with cardiovascular disease in the Third National Health and Nutrition Examination Survey. Atherosclerosis 205, 255-260.

Kesselmeier, J., Eichenberger, W., and Urban, B. (1985). High performance liquid chromatography of molecular species from free sterols and sterylglycosides isolated from oat leaves and seeds. Plant Cell Physiol. 26, 463-471.

Kissmeyer, A. M., and Sonne, K. (2001). Sensitive analysis of $1 \alpha, \quad 25$-dihydroxyvitamin $\quad \mathrm{D}_{3}$ in biological fluids by liquid chromatography-tandem mass spectrometry. J. Chromatogr. A 935 , 93-103.

Klahre, U., Noguchi, T., Fujioka, S. Takatsuto, S., Yokota, T., Nomura, T., et al. (1998). The Arabidopsis DIMINUTO/DWARF1 gene encodes a protein involved in steroid synthesis. Plant Cell 10, 1677.

Kolesnikova, M. D., Xiong, Q., Lodeiro, S., Hua, L., and Matsuda, S. (2006). Lanosterol biosynthesis in plants. Arch. Biochem. Biophys. 447, 87-95.

Kunz, C., Niesen, M., von LilienfeldToal, H., and Burmeister, W. (1984). Vitamin, D, 25-hydroxy-vitamin D and 1,25-dihydroxy-vitamin $\mathrm{D}$ in cow's milk, infant formulas and breast milk during different stages of lactation. Int. J. Vitam. Nutr. Res. 54, 141-148.

Lagarda, M. J., García-Llatas, G., and Farré, R. (2006). Analysis of phytosterols in foods. J. Pharm Biomed. Anal. 41, 1486-1496.

Lappe, J. M., Travers-Gustafson, D., Davies, K. M., Recker, R. R., and Heaney, R. P. (2007). Vitamin D and calcium supplementation reduces cancer risk: results of a randomized trial. Am. J. Clin. Nutr. 85, 1586-1591.

Lees, N., Skaggs, B., Kirsch, D., and Bard, M. (1995). Cloning of the late genes in the ergosterol biosynthetic pathway of Saccharomyces cerevisiae - a review. Lipids 30, 221-226.

Liu, W. H., Ding, B., Ruan, X. M., $\mathrm{Xu}, \mathrm{H}$. T., Yang, J., and Liu, S. M. (2007). Analysis of free and conjugated phytosterols in tobacco by an improved method using gas chromatography-flame ionization detection. J. Chromatogr. A 1163, 304-311.

Lock, E. J., Waagbø, R., and Wendelaar, B. (2010). The significance of vitamin D for fish: a review. Aquacult. Nutr. 16, 100-116.

Lu, B., Zhang, Y., Wu, X., and Shi, J. (2007). Separation and determination of diversiform phytosterols in food materials using supercritical carbon dioxide extraction and ultraperformance liquid chromatography-atmospheric pressure chemical ionization-mass spectrometry. Anal. Chim. Acta 588 , 50-63.

MacLaughlin, J. A., Anderson, R. R. and Holick, M. F. (1982). Spectral character of sunlight modulates photosynthesis of previtamin $\mathrm{D}_{3}$ and its photoisomers in human skin. Science 216, 1001-1003.

Mattila, P., Lampi, A. M., Ronkainen, R., Toivo, J., and Piironen, V. (2002). Sterol and vitamin $\mathrm{D}_{2}$ contents in some wild and cultivated mushrooms. Food Chem. 76 293-298.

Mattila, P., Lehikoinen, K. Kiiskinen, T., and Piironen, V. (1999). Cholecalciferol and 25hydroxycholecalciferol content of chicken egg yolk as affected by the cholecalciferol content of feed. J. Agric. Food Chem. 47, 4089-4092.

Mattila, P., Piironen, V., Haapala, R., Hirvi, T., and Uusi-Rauva, E. (1997). Possible factors responsible for the high variation in the cholecalciferol contents of fish. J. Agric. Food Chem. 45, 3891-3896.

Mattila, P., Piironen, V., UusiRauva, E., and Koivistoinen, P. (1995a). Cholecalciferol and 25hydroxycholecalciferol contents in fish and fish products. J. Food Comp. Anal. 8, 232-243. 
Mattila, P. H., Piironen, V. I., UusiRauva, E. J., and Koivistoinen, P. E. (1995b). Contents of cholecalciferol, ergocalciferol, and their 25hydroxylated metabolites in milk products and raw meat and liver as determined by HPLC. J. Agric. Food Chem. 43, 2394-2399.

Mattila, P. H., Piironen, V. I., UusiRauva, E. J., and Koivistoinen, P. E. (1994). Vitamin D contents in edible mushrooms. J. Agric. Food Chem. 42, 2449-2453.

Mautalen, C. A. (1972). Mechanism of action of Solanum malacoxylon upon calcium and phosphate metabolism in the rabbit. Endocrinology 90, 563-568.

Mello, J. R. B. (2003). Calcinosiscalcinogenic plants. Toxicon 41, $1-12$.

Mezine, I., Zhang, H., Macku, C., and Lijana, R. (2003). Analysis of plant sterol and stanol esters in cholesterol-lowering spreads and beverages using high-performance liquid chromatography - atmospheric pressure chemical ionization - mass spectroscopy. J. Agric. Food Chem. 51, 5639-5646.

Montgomery, J. L., Parrish Jr, F. C., Beitz, D. C., Horst, R. L., HuffLonergan, E. J., and Trenkle, A. H. (2000). The use of vitamin $D_{3}$ to improve beef tenderness. J. Anim. Sci. 78, 2615-2621.

Moore, L. A., Thomas, J. W., Jacobson, W. C., Melin, C. G., and Shepherd, J. B. (1948). Comparative antirachitic value of field-cured hay, barn-dried hay, and wilted grass silage for growing dairy calves. J. Dairy Sci. 31, 489-499.

Moreau, R. A., and Hicks, K. B. (2004). The in vitro hydrolysis of phytosterol conjugates in food matrices by mammalian digestive enzymes. Lipids 39, 769-776.

Moreau, R. A., Whitaker, B. D., and Hicks, K. B. (2002). Phytosterols, phytostanols, and their conjugates in foods: structural diversity, quantitative analysis, and healthpromoting uses. Prog. Lipid Res. 41, 457-500.

Morris, K. M. L., and Levack, V. M. (1982). Evidence for aqueous soluble vitamin D-like substances in the calcinogenic plant. Life Sci. 30, 1255-1262.

Napoli, J. L., Reeve, L. E., Eisman, J. A., Schnoes, H. K., and DeLuca, H. F. (1977). Solanum glaucophyllum as source of 1,25-dihydroxyvitamin D 3 . J. Biol. Chem. 252, 2580-2583.

Natri, A. M., Salo, P., Vikstedt, T., Palssa, A., Huttunen, M., Kärkkäinen, M. U. M., et al. (2006). Bread fortified with cholecalciferol increases the serum 25-hydroxyvitamin D concentration in women as effectively as a cholecalciferol supplement. J. Nutr. 136, 123-127.

Nes, W. D. (2011). Biosynthesis of cholesterol and other sterols. Chem. Rev. 111, 6423-6451.

Newell, S. Y., Arsuffi, T. L., and Palm, L. A. (1996). Misting and nitrogen fertilization of shoots of a saltmarsh grass: effects upon fungal decay of leaf blades. Oecologia 108, 495-502.

Newlander, J. A. (1948). Vitamin D content of roughages. J. Dairy Sci. 455-460.

Newlander, J. A., and Riddell, W. H. (1952). Rate of vitamin D formation in hay. J. Anim. Sci. 11, 419-421.

Norman, A. W. (2006). Vitamin D receptor: new assignments for an already busy receptor. Endocrinology 147, 5542-5548.

Norman, A. W., Nemere, I., Zhou, L. X., Bishop, J. E., Lowe, K. E., Maiyar, A. C., et al. (1992). 1, $25(\mathrm{OH})_{2}$-vitamin $\mathrm{D}_{3}$, a steroid hormone that produces biologic effects via both genomic and nongenomic pathways. J. Steroid Biochem. Mol. Biol. 41, 231-240.

Nyström, L., Moreau, R. A., Lampi, A. M., Hicks, K. B., and Piironen, V. (2008). Enzymatic hydrolysis of steryl ferulates and steryl glycosides. Eur. Food Res. Technol. 227, 727-733.

Nyström, L., Paasonen, A., Lampi, A M., and Piironen, V. (2007). Total plant sterols, steryl ferulates and steryl glycosides in milling fractions of wheat and rye. J. Cereal Sci. 45 106-115.

Ohyama, K., Suzuki, M., Kikuchi, J., Saito, K., and Muranaka, T. (2009). Dual biosynthetic pathways to phytosterol via cycloartenol and lanosterol in Arabidopsis. Proc. Natl. Acad. Sci. U.S.A. 106, 725-730.

Patterson, G. W. (1971). The distribution of sterols in algae. Lipids 6, 120-127.

Patterson, G. W. (1974). Sterols of some green algae. Comp. Biochem. Physiol. B 47, 453-457.

Peterlik, M., Regal, D. S., and Kohler, H. (1977). Evidence for a 1, 25dihydroxyvitamin D-like activity in Trisetum flavescens: possible cause for calcinosis in grazing animals. Biochem. Biophys. Res. Commun. 77, 775-781.

Phillips, K. M., Ruggio, D. M., and Ashraf-Khorassani, M. (2005). Analysis of steryl glucosides in foods and dietary supplements by solid-phase extraction and gas chromatography. J. Food Lipids 12, 124-140.
Piironen, V., Lindsay, D. G., Miettinen, T. A., Toivo, J., and Lampi, A. M. (2000). Plant sterols: biosynthesis, biological function and their importance to human nutrition. J. Sci. Food Agric. 80, 939-966.

Pittas, A. G., Lau, J., Hu, F. B., and Dawson-Hughes, B. (2007). The role of vitamin $\mathrm{D}$ and calcium in type 2 diabetes. A systematic review and meta-analysis. J. Clin Endocrinol. Metab. 92, 2017-2029.

Potocka, A., and Zimowski, J. (2008). Metabolism of conjugated sterols in eggplant. Part 1. UDP-glucose: sterol glucosyltransferase. Acta Biochim. Pol. 55, 127-134.

Prema, T. P., and Raghuramulu, N. (1994). Free vitamin $D_{3}$ metabolites in Cestrum diurnum leaves. Phytochemistry 37, 677-681.

Prema, T. P., and Raghuramulu, N. (1996). Vitamin $D_{3}$ and its metabolites in the tomato plant. Phytochemistry 42, 617-620.

Prosser, D. E., and Jones, G. (2004) Enzymes involved in the activation and inactivation of vitamin $\mathrm{D}$. Trends Biochem. Sci. 29, 664-673.

Rambeck, W., Oesterhelt, W., Vecchi, M., and Zucker, H. (1979). Occurrence of cholecalciferol in the calcinogenic plant Trisetum flavescens. Biochem. Biophys. Res. Commun. 87, 743-749.

Rambeck, W. A., Weiser, H., and Zucker, H. (1984). Biological activity of glycosides of vitamin $\mathrm{D}_{3}$ and $1 \alpha$-hydroxyvitamin $\mathrm{D}_{3}$. Int. J. Vitam. Nutr. Res. 54, 25-34.

Rampen, S. W., Abbas, B. A., Schouten, S., and Damsté, J. S. S. (2010). A comprehensive study of sterols in marine diatoms (Bacillariophyta): implications for their use as tracers for diatom productivity. Limnol. Oceanogr. 55, 91-105.

Rao, D. S., and Raghuramulu, N (1997). Vitamin $\mathrm{D}_{3}$ in Tilapia mossambica: relevance of photochemical synthesis. J. Nutr. Sci. Vitaminol. 43, 425-433.

Rapuri, P. B., Gallagher, J. C., and Haynatzki, G. (2004). Effect of vitamins $\mathrm{D}_{2}$ and $\mathrm{D}_{3}$ supplement use on serum 25OHD concentration in elderly women in summer and winter. Calcif. Tissue Int. 74, 150-156.

Reeve, L. E., Jorgensen, N. A., and DeLuca, H. F. (1982). Vitamin D compounds in cows' milk. J. Nutr. $112,667-672$

Risley, J. M. (2002). Cholesterol biosynthesis: lanosterol to cholesterol. J. Chem. Educ. 79, 377-384.

Rozenberg, R., Ruibal-Mendieta, N. L. Petitjean, G., Cani, P., Delacroix, D. L., Delzenne, N. M., et al. (2003).
Phytosterol analysis and characterization in spelt (Triticum aestivum ssp. spelta L.) and wheat (T. aes tivum L.) lipids by LC/APCI-MS J. Cereal Sci. 38, 189-197.

Ruibal-Mendieta, N. L., Rozenberg, R., Delacroix, D. L., Petitjean, G., Dekeyser, A., Baccelli, C., et al. (2004). Spelt (Triticum spelta L.) and winter wheat (Triticum aestivum L.) wholemeals have similar sterol profiles, as determined by quantitative liquid chromatography and mass spectrometry analysis. J. Agric. Food Chem. 52, 4802-4807.

Russell, W. C. (1929). The effect of the curing process upon the vitamin A and D content of alfalfa. J. Biol. Chem. 85, 289-297.

Sanchez-Machado, D. I., LopezHernandez, J., Paseiro-Losada, P., and Lopez-Cervantes, J. (2004). An HPLC method for the quantification of sterols in edible seaweeds. Biomed. Chromatogr. 18, 183-190.

Sawai, S., Akashi, T., Sakurai, N. Suzuki, H., Shibata, D., Ayabe, S. et al. (2006). Plant lanosterol synthase: divergence of the sterol and triterpene biosynthetic pathways in eukaryotes. Plant Cell Physiol. 47, 673-677.

Schaeffer, A., Bouvier-Navé, P. Benveniste, P., and Schaller, $\mathrm{H}$. (2000). Plant sterol-C24-methyl transferases: different profiles of tobacco transformed with SMT1 or SMT2. Lipids 35, 263-269.

Schaeffer, A., Bronner, R., Benveniste, P., and Schaller, H. (2001). The ratio of campesterol to sitosterol that modulates growth in Arabidopsis is controlled by STEROL METHYLTRANSFERASE 2; 1. Plant J. 25, 605-615.

Schaller, H. (2003). The role of sterols in plant growth and development. Prog. Lipid Res. 42, 163-175.

Schaller, H. (2004). New aspects of sterol biosynthesis in growth and development of higher plants. Plant Physiol. Biochem. 42, 465-476.

Schlatmann, J., Pot, J., and Havinga, E. (1964). Studies on vitamin D and related compounds. XVIII: an investigation into the interconversion of precalciferol and calciferol and of analogous compounds. Rec Trav. Chim. Pay-Bas. 83, 1173-1184.

Schrick, K., Cordova, C., Li, G. Murray, L., and Fujioka, S. (2011). A dynamic role for sterols in embryogenesis of Pisum sativum. Phytochemistry 72, 465-475.

Sitbon, F., and Jonsson, L. (2001). Sterol composition and growth of transgenic tobacco plants expressing type- 1 and type- 2 sterol methyltransferases. Planta 212, 568-572. 
Skliar, M. I., Boland, R. L., Mourino, A., and Tojo, G. (1992). Isolation and identification of vitamin $\mathrm{D}_{3}$, 25-hydroxyvitamin $\mathrm{D}_{3}, 1$, 25-dihydroxyvitamin $\mathrm{D}_{3}$ and 1 , 24, 25-trihydroxyvitamin $\mathrm{D}_{3}$ in Solanum malacoxylon incubated with ruminal fluid. J. Steroid Biochem. Mol. Biol. 43, 677-682.

Skliar, M., Curino, A., Milanesi, L., Benassati, S., and Boland, R. (2000). Nicotiana glauca: another plant species containing vitamin $\mathrm{D}_{3}$ metabolites. Plant Sci. 156, 193-199.

Soldin, O. P., Sharma, H., Husted, L., and Soldin, S. J. (2009). Pediatric reference intervals for aldosterone $17 \alpha$-hydroxyprogesterone, dehydroepiandrosterone, testosterone and 25-hydroxy vitamin $\mathrm{D}_{3}$ using tandem mass spectrometry. Clin. Biochem. 42, 823-827.

Staffas, A., and Nyman, A. (2003). Determination of cholecalciferol (vitamin $\mathrm{D}_{3}$ ) in selected foods by liquid chromatography: NMKL collaborative study. J. AOAC Int. 86, 400-406.

Steenbock, H., Hart, E. B., Elvehjem, C. A., and Kletzien, S. W. F. (1925). Dietary factors influencing calcium assimilation. J. Biol. Chem. 66, 425-441.

Steenbock, H., and Black, A. (1924). Fat-soluble vitamins. J. Biol. Chem. 61, 405.

Suardi, M. L., Bernasconi, S., Pelizzoni, F., and Racchi, M. L. (1994). In vitro cultures of Solanum malacoxylon Sendt.: nutritional requirements and sterol production. Plant Cell Tissue Organ Cult. 36, 9-14.

Sugisaki, N., Welcher, M., and Monder, C. (1974). Lack of vitamin $\mathrm{D}_{3}$ synthesis by goldfish (Carassius auratus L.). Comp. Biochem. Physiol. 49, 647-653.

Sunita Rao, D., and Raghuramulu, N. (1996a). Food chain as origin of vitamin D in fish. Comp. Biochem. Physiol. A 114, 15-19.

Sunita Rao, D., and Raghuramulu, N. (1996b). Lack of vitamin $\mathrm{D}_{3}$ synthesis in Tilapia mossambica from cholesterol and acetate. Comp. Biochem. Physiol. 114, 21-25.

Suzuki, M., Xiang, T., Ohyama, K., Seki, H., Saito, K., Muranaka, T., et al. (2006). Lanosterol synthase in dicotyledonous plants. Plant Cell Physiol. 47, 565-571.
Takeuchi, A., Okano, T., Tanda, M., and Kobayashi, T. (1991). Possible origin of extremely high contents of vitamin $\mathrm{D}_{3}$ in some kinds of fish liver. Comp. Biochem. Physiol. A 100 483-487.

Takeuchi, A., Okano, T., Tsugawa, N., Katayama, M., Mimura, Y., and Kobayashi, T. (1988). Determination of vitamin $\mathrm{D}$ and its metabolites in human and cow's milk. J. Micronutr. Analy. 4, 193-208.

Tanaka, Y., Frank, H., and DeLuca, H. (1973). Biological activity of 1 , 25-dihydroxyvitamin $\mathrm{D}_{3}$ in the rat. Endocrinology 92, 417-422.

Teichmann, A., Dutta, P. C., Staffas, A., and Jägerstad, M. (2007). Sterol and vitamin $\mathrm{D}_{2}$ concentrations in cultivated and wild grown mushrooms: effects of UV irradiation. LWT-Food Sci. Technol. 40, 815-822.

Thomas, J. W. (1952). Antirachitic activity of some dehydrated alfalfa hays and the effect of adding limestone to the grain ration on the development of rickets in calves. J. Dairy Sci. 35, 1107-1116.

Thomas, J. W., and Moore, L. A. (1951). Factors affecting the antirachitic activity of alfalfa and its ability to prevent rickets in young calves. J. Dairy Sci. 34, 916-928.

Toivo, J., Phillips, K., Lampi, A. M., and Piironen, V. (2001). Determination of sterols in foods: recovery of free, esterified, and glycosidic sterols. J. Food Comp. Anal. 14, 631-643.

Trang, H. M., Cole, D. E. C., Rubin, L. A., Pierratos, A., Siu, S., and Vieth, R. (1998). Evidence that vitamin $D_{3}$ increases serum 25-hydroxyvitamin D more efficiently than does vitamin $\mathrm{D}_{2}$. Am. J. Clin. Nutr. 68 854-858.

Uribe, A., Holick, M. F., Jorgensen, N. A., and DeLuca, H. F. (1974). Action of Solanum malacoxylon on calcium metabolism in the rat. Biochem. Biophys. Res. Commun. 58, 257-262.

Van Hoed, V., Zyaykina, N., De Greyt, W., Maes, J., Verhé, R., and Demeestere, K. (2008). Identification and occurrence of steryl glucosides in palm and soy biodiesel. J. Am. Oil Chem. Soc. 85, 701-709.

Vidal, M. C., Lescano, W., Avdolov, R., and Puche, R. C. (1985). Partial structure elucidation of the carbohydrate moiety of 1 , 25-dihydroxycholecalciferol glycoside isolated from Solanum glaucophyllum. Turrialba (IICA) 35, 65-70.

Volkman, J. (2003). Sterols in microorganisms. Appl. Microbiol. Biotechnol. 60, 495-506.

Walling, M. L., and Kimberg, D. V. (1975). Calcium absorption by intestine - stimulation in vitamin D-deficient nephrectomized rats by Solanum glaucophyllum. Gastroenterology 69, 200-205.

Wallis, G. C. (1938). A Comparison of the vitamin $\mathrm{D}$ potency of the stemmy and leafy portions of alfalfa hay. J. Agr. Res. 57, 393-396.

Wallis, G. C. (1939). The vitamin D of alfalfa and prairie hay and its utilization by dairy cows. J. Dairy Sci. 22, 599-606.

Wallis, G. C., Kennedy, G. H., and Fishman, R. H. (1958). The vitamin D content of roughages. J. Anim. Sci. 17, 410-415.

Wasserman, R. H., Corradino, R. A. Krook, L., Hughes, M. R., and Haussler, M. R. (1976a). Studies on the 1 $\alpha, 25$-dihydroxycholecalciferollike activity in a calcinogenic plant, Cestrum diurnum, in the chick. J. Nutr. 106, 457-465.

Wasserman, R. H., Corradino, R. A., and Krook, L. P. (1975). Cestrum diurnum: a domestic plant with 1, 25-dihydroxycholecalciferol-like activity. Biochem. Biophys. Res. Commun. 62, 85-91.

Wasserman, R. H., Henion, J. D. Haussler, M. R., and McCain, T. A. (1976b). Calcinogenic factor in Solanum malacoxylon: evidence that it is 1, 25-dihydroxyvitamin $\mathrm{D}_{3}$ glycoside. Science 194, 853-855.

Wasserman, R. H. (1974). Calcium absorption and calcium-binding protein synthesis: Solanum malacoxylon reverses strontium inhibition. Science 183, 1092-1094.

Waterham, H. R., Koster, J., Romeijn, G. J., Hennekam, R., Vreken, P. Andersson, H. C., et al. (2001). Mutations in the 3 $\beta$-hydroxysterol $\Delta 24$-reductase gene cause desmosterolosis, an autosomal recessive disorder of cholesterol biosynthesis. Am. J. Hum. Genet. 69, 685-694.

Weissenberg, M., Levy, A., and Wasserman, R. H. (1989). Distribution of calcitriol activity in Solanum glaucophyllum plants and cell cultures. Phytochemistry 28, 795-798.

Weissenberg, M., Maoz, A., Levy, A., and Wasserman, R. H. (1988). Radioimmunoassay for rapid estimation of vitamin D derivatives in calcinogenic plants. Planta Med. 54, 63-65.

Whitaker, B. D. (1988). Changes in the steryl lipid content and composition of tomato fruit during ripening. Phytochemistry 27, 3411-3416.

Whitaker, B. D. (1991). Changes in lipids of tomato fruit stored at chilling and non-chilling temperatures. Phytochemistry 30, 757-761.

Windaus, A. (1931). The chemistry of irradiated ergosterol. Proc. R. Soc. Lond. B Biol. Sci. 108 568-575.

Yeung, B., and Vouros, P. (1995). The role of mass spectrometry in vitamin D research. Mass Spectrom. Rev. 14, 179-194.

Zucker, H., Stark, H., and Rambeck, W. A. (1980). Light-dependent synthesis of cholecalciferol in a green plant. Nature 283, 68-69.

Zygadlo, J. A. (1993). A comparative study of sterols in oil seeds of Solanum species. Phytochemistry $35,163-167$.

Conflict of Interest Statement: The authors declare that the research was conducted in the absence of any commercial or financial relationships that could be construed as a potential conflict of interest.

Received: 15 March 2013; accepted: 22 April 2013; published online: 13 May 2013.

Citation: Jäpelt $R B$ and Jakobsen (2013) Vitamin D in plants: a review of occurrence, analysis, and biosynthesis. Front. Plant Sci. 4:136. doi: 10.3389/fpls. 2013.00136

This article was submitted to Frontiers in Plant Physiology, a specialty of Frontiers in Plant Science.

Copyright (c) 2013 Jäpelt and Jakobsen. This is an open-access article distributed under the terms of the Creative Commons Attribution License, which permits use, distribution and reproduction in other forums, provided the original authors and source are credited and subject to any copyright notices concerning any third-party graphics etc. 